Portland State University

PDXScholar

5-23-1986

\title{
Attitudes of Otolaryngologists Towards Speech Pathologists Working with Voice Disordered Clients
}

Judith Patricia-Bader Cross

Portland State University

Follow this and additional works at: https://pdxscholar.library.pdx.edu/open_access_etds

Part of the Speech and Rhetorical Studies Commons, and the Work, Economy and Organizations Commons

Let us know how access to this document benefits you.

\section{Recommended Citation}

Cross, Judith Patricia-Bader, "Attitudes of Otolaryngologists Towards Speech Pathologists Working with Voice Disordered Clients" (1986). Dissertations and Theses. Paper 3587.

https://doi.org/10.15760/etd.5471

This Thesis is brought to you for free and open access. It has been accepted for inclusion in Dissertations and Theses by an authorized administrator of PDXScholar. Please contact us if we can make this document more accessible: pdxscholar@pdx.edu. 
AN ABSTRACT OF THE THESIS OF Judith Patricia-Bader Cross for the Master of Science in Speech Communication presented May 23, 1986.

Title: Attitudes of Otolaryngologists Towards Speech Pathologists Working with Voice Disordered $\mathrm{Cl}$ ients

APPROVED BY MEMBERS OF THE THESIS COMMITTEE:
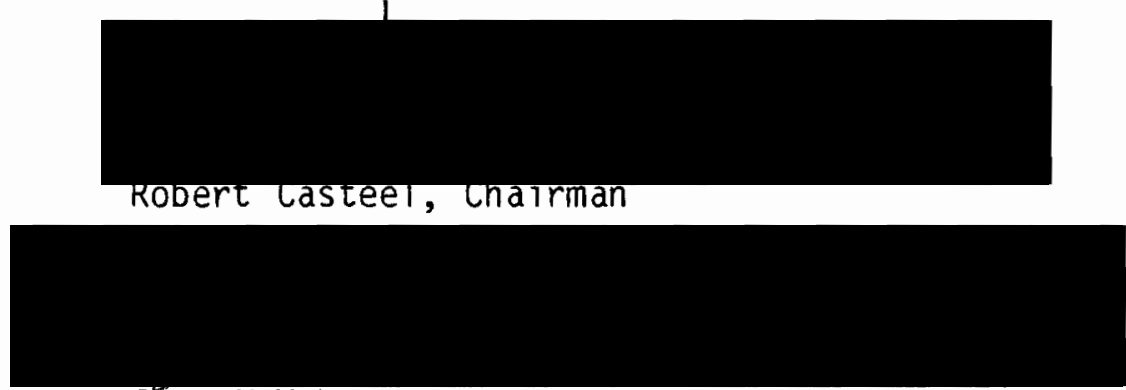

Joan McMahon

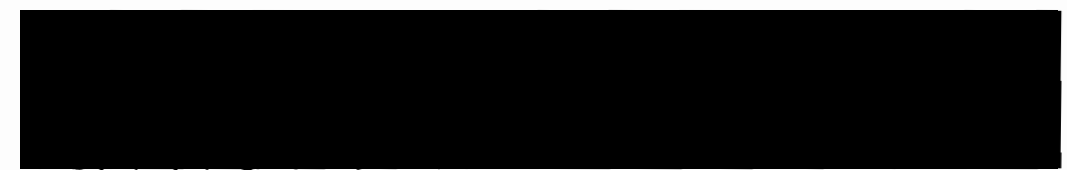

Richard Sonnen

This study was designed to collect information about the working relationship of otolaryngologists with speech pathologists who provide service to voice disordered clients.

Otolaryngologists in Oregon, Nevada, and Washington were sent questionnaires which asked for information related to the four following questions: what exposure did the respondents have to speech pathology in their medical training experience; what professional contact do the 
respondents have with speech pathologists in their practices; what knowledge do the respondents have of a speech pathologist's general education and specific training in voice disorders; and on a semantic differential scale, how did the respondents react to position statements drawn from opinions expressed by otol aryngologists.

Because of the overall very low rate of response to this study, it was difficult to draw many conclusions. Those who did respond varied in caseload size, practice areas, sites and dates of nonspecialty and specialty training. They tended to have a fair amount of professional contact with speech pathologists and make referrals to speech pathologists. The subjects who answered the questionnaire generally were unsure of the training requirements of a speech pathologist. Most agreed that speech pathology intervention was appropriate in the given list of disorders.

The respondents attitudes tended to be generaliy favorable to speech pathologists, except in the area of diagnosis. Whether the speech pathologist's use of the concept of diagnosis was unclear to the respondents or they firmly claim ownership of this word was difficult to determine. 
ATTITUDES OF OTOLARYNGOLOGISTS TOWARDS SPEECH

PATHOLOGISTS WORKING WITH VOICE

DISORDERED CLIENTS

by

JUDITH PATRICIA-BADER CROSS

A thesis submitted in partial fulfillment of the requirements for the degree of

MASTER OF SCIENCE IN SPEECH COMMUNICATION:

with an emphasis in

SPEECH PATHOLOGY/AUDIOLOGY

Portland State University

1986 
TO THE OFFICE OF GRADUATE STUDIES AND RESEARCH:

The members of the Committee approve the thesis of Judith Patricia-Bader Cross presented May 23, 1986.

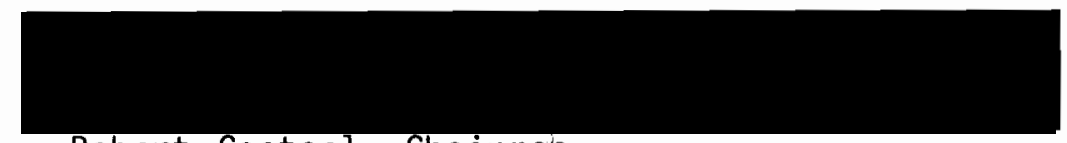

Robert Casteel, Chairman

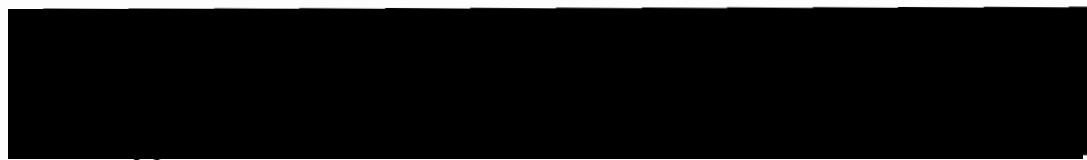

Jasan McMahon

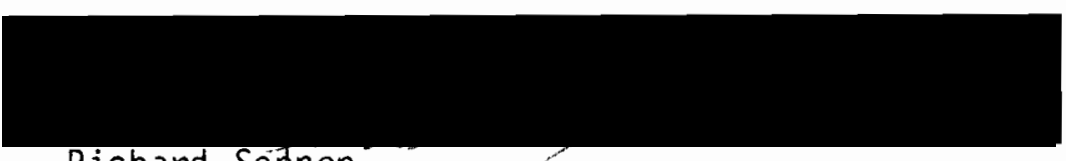

Richard Sonnen

APPROVED:

Theodore Grove, Head, depar ument of Speecn communtcation

Bernard Ross, Dean of Graduate Studies and Research 


\section{ACKNOWLEDGEMENTS}

Sometimes, not often enough, we are given the opportunity to acknowledge those people who have made a difference in our lives. I consider the completion of this thesis just such an opportunity.

The members of my family have influenced me with their ideals about the importance of an education as $l 1$ as a sense of the value of a close family. They have given me support and gentle prodding to achieve.

My colleagues from my university training gave me friendship and a positive environment in which to learn. I admire them as professionals and as human beings.

My friends outside the field of speech-language pathology have given me a sense of humor and many hours of patient listening.

I thank God for the ability to learn and the ambition to endure the challenges of acquiring an education.

Finally, I dedicate this thesis to Pat, who has given me strength, confidence and love. The words to one of my favorite songs read: "Ever together like the sun and the moon give each other room, to shine and to glow and to grow and to know that I love you". Thank you, Pat, for allowing me to shine and grow because I know that I love you. 
TABLE OF CONTENTS

Page

ACKNOWLEDGEMENTS

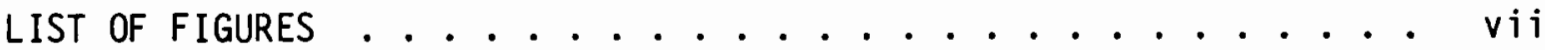
CHAPTER

I INTRODUCTION AND STATEMENT OF THE PROBLEM . . . . . . . 1

Introduction ................. 1

Statement of the Problem ............ 2

II REVIEW OF THE LITERATURE . . . . . . . . . . . . 3

History................. 3

Training for the Certificate of $\mathrm{Cl}$ inical Competence . . 6

The Debate Over Professional Autonomy . . . . . . . 8

A Team Approach for Voice Disorders . . . . . . . 10

Factors Affecting a Physician's Use of Speech

Pathologists ............... 12

II METHODS ................... 15

Subjects ................... 15

Survey Design . . . . . . . . . . . 15

Coding . . . . . . . . . . . . . . 16

Mailing .................... 17

Data Processing . . . . . . . . . . . 17

Data Analysis ............... . . 17 
IV RESULTS .............................. 19

Profile of Respondents ........... 19

Patient Information

Population Served by Subjects

Education of Subjects

Education in Speech Pathology

Subjects' Contact with Speech Pathologists . . . . .

Referrals Made to Speech Pathologists

Referrals Received from Speech Pathologists

Direct Contact with Speech Pathologist

Subjects' Knowledge of Speech Pathologists ......

Voice Disorders with Which Speech Pathologists are

Helpful

Textbooks Influencing Subjects' Knowledge

Subjects' Reactions to Position Statements . . . . 36

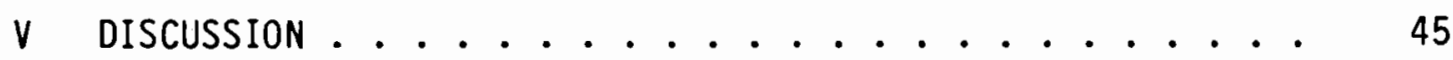

Profile of Respondents ............ 45

Professional contact ............. 47

Knowledge ................... 4 47

Subjects' Reactions to Position Statements . . . . 48

VI SUMMARY AND CONCLUSIONS ................. 53

Summary ................. . . 53

Conclusions ............... . . . . 54

Implications for Future Research . . . . . . . 55

BIBLIOGRAPHY ..................... 57 
vi

Page

APPENDICES . . . . . . . . . . . . . . . . . . . .

60

A Cover Letter to all Respondents . . . . . . . . 60

B Informed Consent Form .............. 62

C Questionnaire ................ 64

D Cover Letter to Nevada Subjects . . . . . . . . 68

E Follow-up Postcard ................. 70 


\section{LIST OF FIGURES}

1 Percentage of respondents from each state surveyed . . . 20

2 Total number of patients seen per month as reported by respondents .............. . . 21

3 Total number of voice disordered patients seen per year as reported by respondents ........... 22

4 Population size of area served by respondents . . . . . 23

5 Respondents acquiring their medical degree training and post medical degree (specialty) training during specific time periods from 1951 to the present . . . 25

6 Number of total referrals made to speech pathologists per year by respondents . . . . . . . . . 30

7 Disorders for which respondents noted as appropriate for speech pathology intervention .......... 31

8 Total number of referrals received from speech pathologists by respondents ........... 32

9 Respondents' contact with speech pathologists (including phone calls) ..............

10 Respondents' knowledge of the educational level of speech pathologists ...............

11 Respondents' knowledge of the requirements for the Certificate of $\mathrm{Cl}$ inical Competence .........

12 Voice disorders for which respondents view speech pathologists helpful ........... 36

13 Respondents' reaction to position statement 1..... . 37

14 Respondents' reaction to position statement 2...... 38 
15 Respondents' reaction to position statement $3 \ldots 39$

16 Respondents' reaction to position statement 4 ...... 40

17 Respondents' reaction to position statement 5 ...... 41

18 Respondents' reaction to position statement 6 ...... 42

19 Respondents' reaction to position statement $7 \ldots 43$

20 Respondents' reaction to position statement $8 \ldots 44$

21 The mode of responses to each position statement . . . . 49 


\section{CHAPTER I}

\section{INTRODUCTION AND STATEMENT OF THE PROBLEM}

\section{Introduction}

One of the roles of speech pathologists dealing with voice problems is to act as a member of a team of specialists. The most important members of this team are the speech pathologist and the medical voice specialist.

Although speech pathologists have long regarded the involvement of medical professionals as imperative, the medical professional's attitudes toward speech pathologists have varied and become quite controversial. In February, 1983, the Journal of the American Speech-Language-Hearing Association (ASHA) published the policies of the American Academy of Otolaryngologists (AAO) in which the "traditional role of the physician in the diagnosis and treatment of hearing and speech disorders" was reaffirmed. The AAO stated that any group, other than physicians, that contended to be capable of diagnosing and/or managing speech disorders without medical supervision constitutes a "menace to the health of the nation."

Then ASHA president, F. Minifie, in an address to the Oregon Speech-Language-Hearing Association in October, 1983, explained the events following this position statement. He contacted the present president of the $A A O$ who agreed that perhaps the position statement needed revising. After conferring with other members of the AAO, however, he stated that we 
"should work for a more cooperative relationship but the AAO said that the historical perspective indicated the original position statement was appropriate," (Minifie, 1983b).

The various comments in the literature and the discussion of differing viewpoints among members of the AAO lead to the question of what are the attitudes of most laryngologists toward speech pathologists working with voice disordered $\mathrm{clients.} \mathrm{More} \mathrm{important} \mathrm{is} \mathrm{the} \mathrm{effect} \mathrm{these}$ attitudes have on the working relationship between speech pathologists and otol aryngologists.

Statement of the Problem

The purpose of this study was to collect information about the working relationship of otolaryngologists with speech pathologists who provide service to voice disordered clients.

The information this study sought to gather was:

What exposure did the respondents have to speech pathology in their medical training experience?

What professional contact did the respondents have with speech pathologists in their practice?

What knowledge did the respondents have of a speech pathologist's general education and specific training in voice disorders?

On a semantic differential scale, how did the subjects react to position statements drawn from opinions expressed by otol aryngologists? 
CHAPTER II

REVIEW OF THE LITERATURE

Introduction

Many passing comments about the topic of the present research occur in the literature; however, it appears that previous studies even remotely similar to the present study are nonexistent. Therefore the review of the literature might be described more accurately as "background information."

This background information will include a brief description of the history of voice intervention; the training for individuals who hold a Certificate of Clinical Competence in Speech-Language Pathology; the interdisciplinary debate over professional autonomy; a discussion of a team approach for voice disorders; and factors affecting a physician's collaboration with speech pathologists.

\section{Discussion}

History

Laryngology as a recognized specialty is just over one hundred years old. Speech pathology as an organized entity within rehabilitation has 
existed a little more than half that time. The treatment, however, of disease affecting the vocal mechanism and remediation efforts with disorders of communication have ancient and varied roots.

Singing and training of the singing voice probably began in antiquity. There is evidence that the Greek and Roman schools of oratory attended to voice and speech training. Schools of theatre which go back many centuries have always included the use of voice and speech. In the 1700 's and 1800's, voice training in education became known as the Elocutionary movement. Elocution in the United States followed the British tradition until the early 1800 's. At this time, it is believed, medical science and speech joined together in the United States when J. Rush, a physician with an interest in speech and voice, published Philosophy of the Human Voice. In Europe in the late 1800's and early 1900's, there were a number of primarily medical specialists interested in the rehabilitation of disorders of speech, directed for the most part to stuttering, cleft palate, and aphonia. During this time speech pathology grew within the educational setting in the United States (Moore, 1981).

During this period, Gutzmann attracted physicians to study speech disorders from a medical viewpoint. Fritzell (1980) reports that the term "phoniatrie" was coined in 1919 by Stern in Vienna for the medical specialty of speech, language, and voice disorders. Froeschels used the term "logopedie" to denote the same specialty. Before World War I, Froeschels developed an outpatient clinic for voice and speech disorders in Vienna where physicians could acquire training. In 1924, the International Association of Logopedics and Phoniatrics was founded in Vienna. 
Phoniatrics became the medical specialty and logopedics became the pedagogical, psychological, and therapeutic branch.

According to Segre (1971) the medical profession as a whole has shown little interest in phoniatrics and logopedics. In Segre's report almost none of the surveyed countries' medical schools included these subjects in the ir medical curriculum. The report found, however, that where speech pathology associations had a large membership which included physicians and other related professionals, the status of logopedics and phoniatrics was excellent. In the United States, as of Segre's report of 1971, phoniatrics and logopedics was rarely part of the school of medicine and there was no phoniatric instruction offered to medical students. In a 1977 report by the National Institute of Neurological and Communication Disorders and Stroke (NINCDS), forty-four percent of the surveyed United States medical schools offered speech and language subspecialty instruction. This is in spite of the fact that at the time of NINCDS report, speech and language was not recognized as an important aspect for otolaryngologists' training and was not included in the examination for certification from the American Board of 0tol aryngology.

Few of the programs surveyed had faculty competent to teach in the subspecialty of speech and language. Therefore, these areas were obtained from another department in the school such as the Speech Department. The report noted that because training from other departments may not provide emphasis needed by otolaryngologists, the overall training of the residents is weakened (NINCDS, 1977).

A report in 1980 by Fritzell found 19 countries that officially 
recognized the field of phoniatrics, all of which were in Europe or Latin America. The report commented that phoniatrics was undergoing a rapid development, gaining official status in many countries, being initiated in many training programs and the number of phoniatricians was increasing. At the time of this report there were approximately 300 full time phoniatrists.

Alberti (1980) found very few training programs where otolaryngologists were "taught to listen" to the voice and few programs where speech pathologists were invited to tell the residents in training what speech pathologists do. In a 1984 interview printed in the American Speech-Language-Hearing Association (ASHA) Journal, D. 0ldring, M.D., noted that otolaryngologists generally are not schooled in the terms or strategies that speech pathologists use, and they try to acquire this in their residency training by having instruction and exposure to speech pathology. The findings of the 1977 NINCDS report indicated that otolaryngologists are interested in this exposure. Eighty-seven percent of the surveyed otolaryngologists in training in the United States listed availability of non-otolaryngological colleagues for consultation as an important factor in determining their chosen practice site.

\section{Training for the Certificate of Clinical Competence}

The individual tho is awarded the Certificate of $\mathrm{Cl}$ inical Competence (CCC) from the American Speech-Language-Hearing Association must hold a 
masters degree or its equivalent with a major emphasis in speech-language pathology. The academic training must provide in-depth knowledge of normal communication processes, development and disorders thereof, evaluation procedures to assess the bases of such disorders, and clinical techniques that have been shown to improve or eradicate them. The individual with a CCC must have completed a minimum of 300 clock hours of supervised clinical experience with individuals who present a variety of communication disorders. A minimum of twenty-five of these clock hours must be in the management of voice disorders. Following completion of the academic and clinical practicum, the individual must obtain the equivalent of nine months of full time professional experience known as the $\mathrm{Cl}$ inical Fellowship Year. Finally, the individual holding a CCC must pass the National Examination in speech-language pathology.

Until these requirements were created there was no way to guarantee minimum standards of training for voice intervention. The voice area was recognized by Williamson (1946) as one of the "weakest links in the armor of most of our clinicians." In 1966, Brodnitz, an otolaryngologist, commented that voice is still a "stepchild" of the training programs in speech pathology. At that time, Brodnitz found the number of training programs which did not include systematic training in the handling of voice disordered-patients "uncomfortably high."

Aronson (1980) found that speech pathologists' training in voice disorders is among the "least satisfactory." This is due to speech pathologists questioning the value of voice intervention as well as a limited variety of referrals from otolaryngologists. 
McFarlane, Fujiki, and Brinton (1984) describe the specific practices for which a speech pathologist is trained. Speech pathologists evaluate speech, language, voice, and fluency, not the larynx, brain, tongue. or any other mechanical structure. Speech pathologists do evaluate the effect of these structures on the acoustic and linguistic output. Speech pathologists make diagnostic statements about speech, voice, fluency, and language, and not about physical pathology. Speech pathologists determine the appropriateness of voice, articulation, fluency, or language intervention and determine the exact process of intervention. By education and training the speech pathologist is "far more extensively prepared to screen, evaluate, diagnose, treat, and counsel patients about speech and language disorders than any other professional" (McFarlane et al., 1984).

\section{The Debate Over Professional Autonomy}

In the December 1981 issue of the American Council of Otolaryngology Newsletter (reported in ASHA, by Wilbur, 1982) the statement was made that:

It is against the public interest for the audiologist or speech pathologist to manage hearing or speech symptomatology without medical consultation with a physician knowledgeable in diseases of the ear, nose, and throat.

Then president of ASHA, L.A. Wilbur, responded to the American Academy of Otolaryngology (AAO) by taking exception to the position statement which "confused medical supervision with medical consultation." Subsequently the $A A O$ published an official policy statement in the 
September 1982 issue of the AAO-HNS Bulletin (reprinted in ASHA, February, 1983) which reaffirmed the "traditional role" of the physician in the diagnosis and treatment of hearing, speech, and equilibratory disorders. The AAO stated that:

The expressed or implied contentions of any group, other than physicians, that they are capable of diagnosing or managing speech, vestibular, and hearing disorders without medical supervision constitutes a menace to the health of the nation and is not in the public interest.

The new president of ASHA, F. Minifie: responded by letter to the policy statement (Minifie, 1983a). He chose not to focus on each point of conflict in the statement, but on the "underlying theme that speech, language, hearing, and vestibulary evaluation and rehabilitation is the exclusive supervisory and treatment domain of the physician or otolaryngologist." Minifie commented that this posture by the AAO "inflamed traditional attitudes and beliefs related to territorial domain." Minifie called for revision of the position statement or at least a rescinding of the more offensive of the items.

In a subsequent letter from Minifie to ASHA members (Minifie, 1983c), Minifie discussed his conversations with AAO president, G. Sisson. Sisson expressed great optimism in his original meeting with Minifie; however, after preliminary investigation sisson found little interest in forming a liason committee between the two societies. Sisson agreed that a more 
cooperative relationship would be beneficial but the association (AAO) felt strongly that the original position statement was appropriate based on the "historical perspective."

At this point the question of maintaining professional autonomy while enhancing a cooperative relationship between the medical profession and the field of Speech Pathology/Audiology remains a major issue.

\section{A Team Approach for Voice Disorders}

The concept of a team approach in working with voice disordered clients is not new. In the early 1900 's the forming of the International Association of Logopedics and Phoniatrics (as previously discussed) was recognized as the teaming of the medical specialists (phoniatrists) and the psychologists, therapists, and pedagologists (logopedists).

Through the years, authors have written about the importance of this team approach for voice disorders. Arnold (1958) stated that the collaboration between the fields of speech pathology and otolaryngology allows for the selection of the best intervention strategy. Bloch (1959) called for allied fields (including otol aryngology, phoniatrics, neurology, psychiatry, psychology, pedagogics, phonetics, dramatic art, and applied acoustics) to collaborate rather than separate, on an "integrated enterprise." Deweese and Lillywhite (1960) discussed the alliance between speech pathologists and the medical profession because of mutual interest in the vocal mechanism. O'Neill and McGee (1962) wrote about the "antiquated approach" which views lesions of the vocal mechanism as purely mechanical with the treatment being their simple removal. This view should 
be replaced with a "more accurate broader concept" of considering all phases of treatments: preoperative, operative, and postoperative. 0'Neill and McGee viewed the otolaryngologists' (like themselves) closest ally in the application of this approach to be the speech pathologist. Cooper and Nahum (1967) went so far as to say that one of the major causes of unsuccessful treatment of voice disorders is the lack of "understanding and communication" between speech pathologists and otolaryngologists.

More recently Bloch, Gould, and Hirano (1981) concluded that the research emphasizes the importance of a team approach to management of voice disorders. Aronson (1980) stated that contact between the speech pathologist, the otolaryngologist, and the patient gives the patient a feeling of mutual cooperation among the professionals who are treating him. This contact allows for the continuing education of both the speech pathologist and the otolaryngologist as well as attending to the total care of the voice disordered patient.

One example of this teamwork in action is the teaming of speech pathologists, otolaryngologists, and voice coaches in treating problems with the professional voice. The Voice Foundation of America is an organization dedicated to educating and unifying the specialists who work with voice in various capacities. For the past 15 years, the Voice Foundation has seen rapidly increasing interest and involvement in their annual symposium on the Care of the Professional Voice.

Another example of this teamwork between the speech pathologist and otolaryngologist is the development and implementation of the public school diagnostic voice clinic. A local school district speech pathologist 
collects referrals, screens, and selects students for the voice clinic. During the voice $\mathrm{clinic}$ the otolaryngologist examines the referred student's vocal mechanism for possible medical conditions.

The diagnostic team voice clinic was established for a number of reasons. Cooper (1973) described the difficulty speech pathologists have in dealing with voice disorders in the public schools. One such problem was the public schools' "channels" of administration. Another difficulty was that parents of voice disordered students are often unable or unwilling to assume the financial burden of obtaining a laryngeal examination because they do not perceive a voice disorder medically or educationally affecting their child.

Miller and Madison (1984) found public school voice clinics to be valuable in providing an opportunity for speech pathologists like themselves to work more closely with medical professionals. Children who would have received no diagnosis or treatment for laryngeal pathology have been quickly and efficiently processed, and school personnel and the community have learned about voice problems through participation in such clinics.

\section{Factors Affecting Physicians' Use of Speech Pathologists}

The 1977 NINCOS report discussed a number of pertinent findings about the "employment" of speech pathologists by otolaryngologists. The report did not define the term "employment"; however, the report did define the term "ancillary personnel" (which included speech pathologists) as describing certain personnel who work in conjunction with the physician. 
Otolaryngologists who worked in conjunction with speech pathologists tended to have a lower than average number of patients per month. This finding was seen largely because speech pathologists are more prevalent in university medical center settings where the patient visit average is lower. A relatively low percentage (6.9\%) of all otolaryngologists are in university medical center setting; however, a moderate amount of otolaryngologists (33\%) who work with speech pathologists are in university medical centers.

Otolaryngologists who work with speech pathologists tended to be younger in age than the average otolaryngologists. This finding suggests that those otolaryngologi.sts more recently exposed to medical school training may be more aware of the positive aspects of working in conjunction with speech pathologists (NINCDS, 1977).

The NINCDS report speculated that had speech pathologists been available, the surveyed otolaryngologists might have been more likely to collaborate with them. However, 50.8 percent of the surveyed otolaryngologists said speech pathologists were available in the community while only 11.1 percent of those surveyed actually worked with them.

The literature addressed the quality of a physician's use of speech pathologists as well as the quantity. The physician needs to "wholeheartedly" endorse the speech pathologist's program in order for voice intervention to be effective (Cooper, 1971). The physician does this by reporting laryngological findings and their significance to the speech pathologist (0'Neill and McGee, 1962). The physician needs to support the authority of the speech pathologist by encouraging the voice disordered 
patient to follow through with instruction from the speech pathologist, realizing that voice intervention often requires a great deal of time and energy (DeWeese and Lillywhite, 1960; Greene, 1980). 
CHAPTER III

METHODS

Subjects

The subjects of this study were otolaryngologists currently practicing in the states of Oregon, Washington, and Nevada. The names were acquired from the Directory of Medical Specialists: Twenty-First Edition $\underline{(1983-1984)}$.

\section{Survey Design}

A number of strategies were specifically utilized in the designing of the questionnaire.

The response formats for the questionnaire were closed type of questions including two way questions (i.e., yes/no), multiple choice questions, and ranking scales; and open ended questions (asking for specific information from the subjects without choices being given).

Several general guidelines were used in designing multiple choice questions and two way questions. Each question related to one idea and questions were kept short, simple, and direct. Familiar terms were used. Every effort was made to use unbiased words and phrases, and questions were asked positively.

The ranking scale used was the Semantic Differential Scale. 
Utilizing this format, subjects rated a given statement along a seven point scale of bipolar adjectives (agree/disagree). The scale looks at the direction of the attitude (positive/negative) and the intensity or strength of the attitude (how far out each side of the scale the subjects marks) (Edwards, 1957). For the purpose of reporting information, the following descriptors were designated for each numeral on the scale: 1-strongly agree, 2-moderately agree, 3-agree somewhat, 4-no strong opinion either way, 5-disagree somewhat, 6-moderately disagree, and 7-strongly disagree. The statements in the ranking scale were acquired from informal discussions with otolaryngologists and editorial comments contained in the literature. These comments were used as a guide to construct statements using the following criteria: avoid statements referring to the past rather than the present; avoid statements that are likely to be endorsed or rejected by all respondents; keep the language of the statements simple, clear, and direct; keep the statements short, generally not more than twenty words; each statement should have only one complete thought; avoid language such as "all, always, none, never"; and avoid words that may not be understood by the respondents (Edwards, 1957).

\section{Coding}

Each questionnaire was number coded. The subjects were instructed to "mail the consent letter signed and dated and the filled questionnaire in the enclosed envelope". When received, the consent letter was removed from the questionnaire and the subject was checked off on a master list coded by numbers . 


\section{Mailing}

On July 8, 1985, each otolaryngologist in the aforementioned areas was sent a cover letter (Appendix A), a consent form (Appendix B), a questionnaire (Appendix C), and a stamped self-addressed return envelope. In addition, the Nevada subjects were sent a personal request to participate from Stephen McFarlane, Ph.D., Speech Pathologist, at the University of Nevada at Reno Medical School (Appendix D).

On August 5, 1985 (four weeks after the initial mailing) postcards were sent to nonrespondents reminding them to participate (Appendix E).

\section{Data Processing}

When each questionnaire was received, the information was entered into a master data file using the coded numbers.

\section{Data Analysis}

The data collected were reported in terms of percentage of the total number of responses to each specific question. For example, if only thirty-nine subjects responded to a particular item and fourteen of those thirty-nine marked yes, the data would be reported as the percentage of fourteen of thirty-nine. To illustrate the massive amount of data collected, many graphs and tables were used.

The method used to analyze the data collected is defined as descriptive statistics. The method of sample statistics could not be utilized because it requires evidence of validity and reliability of the data collected. Validity is the assurance that the data collected 
represented the population surveyed. Because of the small number of respondents to this study, it is difficult to conclude that the findings represent the total population. Reliability is the assurance that the subjects' responses will be consistent from one instance to the next. The reliability of the collected data is difficult to assure because of the lack of a test/retest reliability check. This check is given to a small sample of subjects on two occasions and the similarity of the responses from one occasion to the next is compared. 
CHAPTER IV

RESULTS

The data reported in the ensuing discussion relates to the following study questions: what exposure did the respondents have to speech pathology in their medical training experience (including a general profile of those who responded); what professional contact did the respondents have with speech pathologists in their practice; what knowledge did the respondents have of a speech pathologist's general education and specific training in voice disorders; and on a semantic differential scale, how did the subjects react to position statements drawn from opinions expressed by otol aryngologists.

The data collected is reported in terms of percentages of the total number of responses to each specific question, as described in the Data Analysis discussion.

\section{Profile of Respondents}

A total of 252 questionnaires were sent to otolaryngologists in Oregon (93 subjects), Washington (132 subjects), and Nevada (27 subjects). of the total, 7 were returned as undeliverable by the post office and 3 were returned unanswered for various reasons (subject's practice limited to otology, subject retired, and subject deceased). Of a total possible 242 
subjects, 41 (17\%) responded to the study.

In the state of Washington, 18 (14\%) of a total possible 127 subjects responded. In the state of Oregon 18 (17\%) of a possible 92 subjects responded. In the state of Nevada, 5 (22\%) of a total possible 23 subjects responded (see Figure 1).
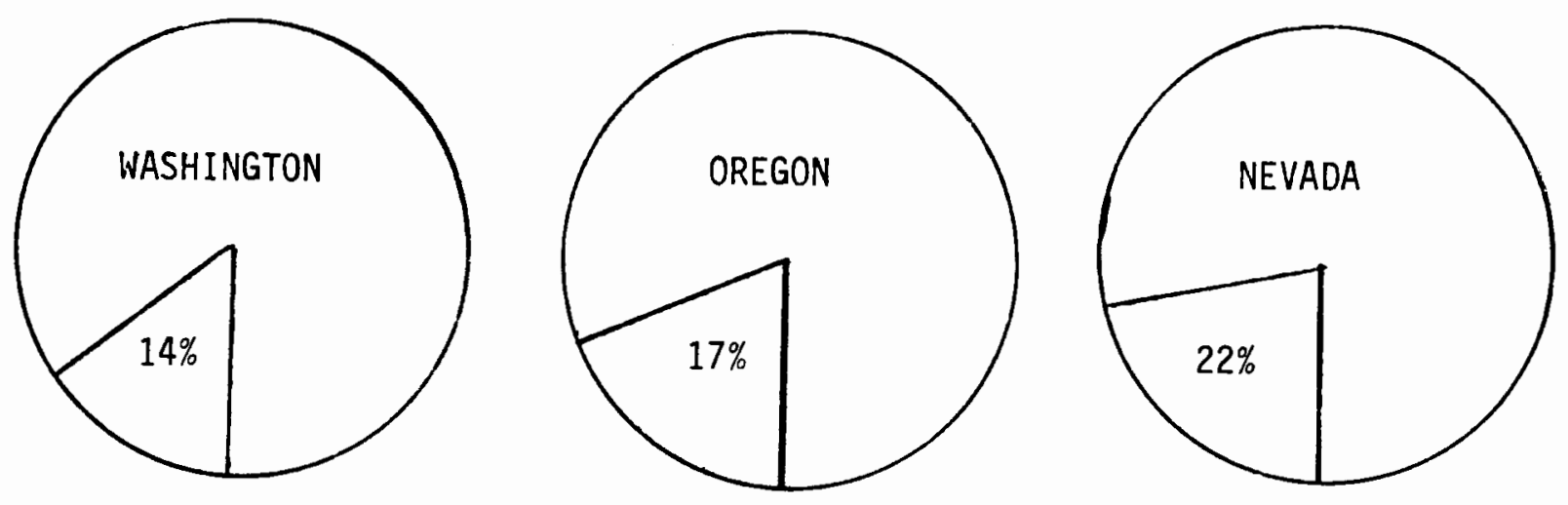

FIGURE 1. Percentage of respondents from each state surveyed.

Patient Information

In reporting the number of patients seen per month 2 subjects (5\%) treated less than 100 patients each month, 2 subjects (5\%) saw 100 to 150 patients per month, 9 respondents (22\%) saw 150 to 200 patients per month, and the majority of otolaryngologists in this study, 28 subjects (68\%), treated over 200 patients per month (see Figure 2). 


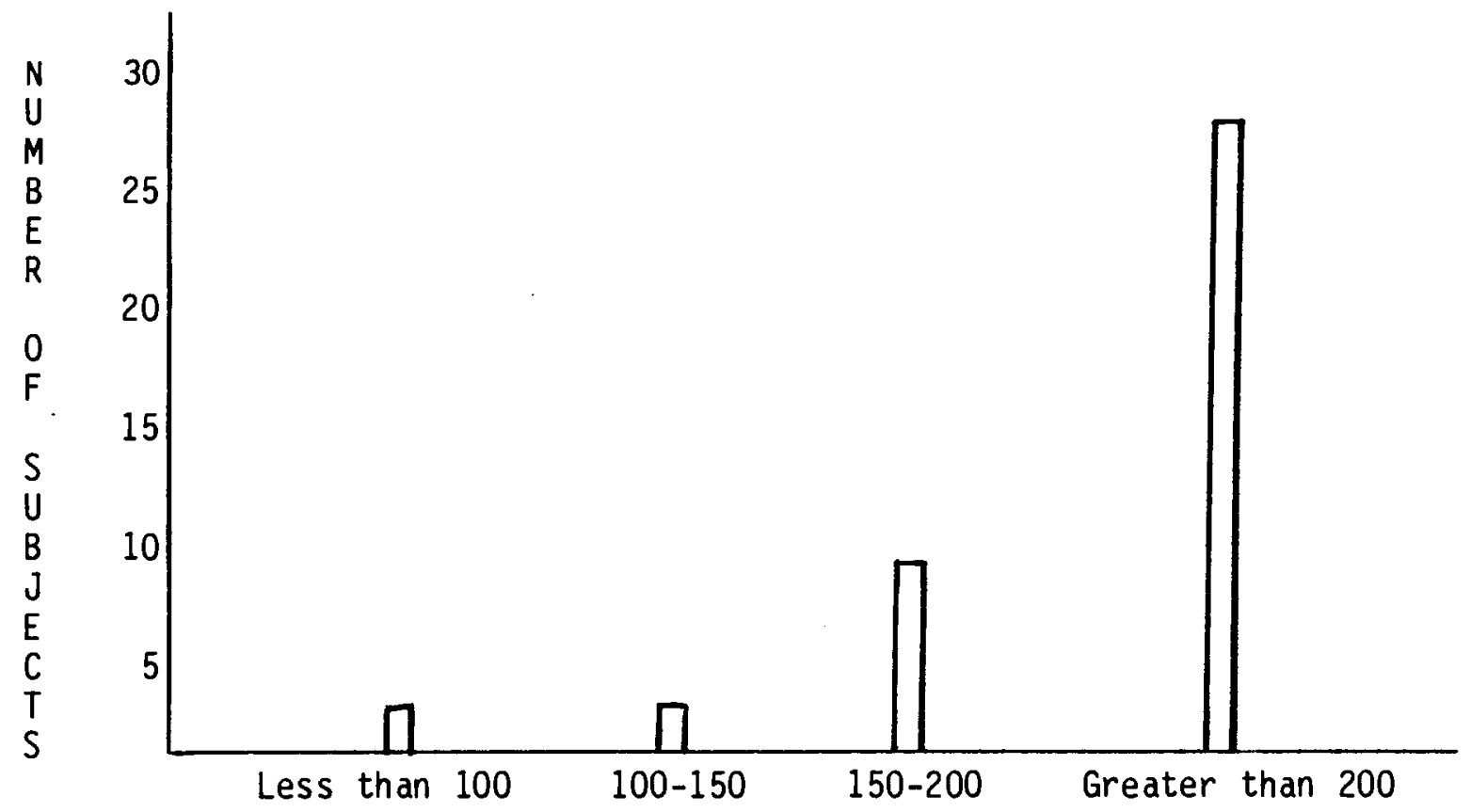

FIGURE 2. Total number of patients seen per month as reported by respondents.

Subjects were asked the number of voice disordered patients seen each year. Two subjects (5\%) reported seeing less than 5 voice disordered patients per year, 12 respondents (29\%) saw 5 to 20 voice disordered patients per year, the greatest percentage of respondents, 21 (51\%), saw 21 to 100 voice disordered patients per year, and 6 subjects (15\%) saw over 100 voice disordered patients per year (see Figure 3 ). 


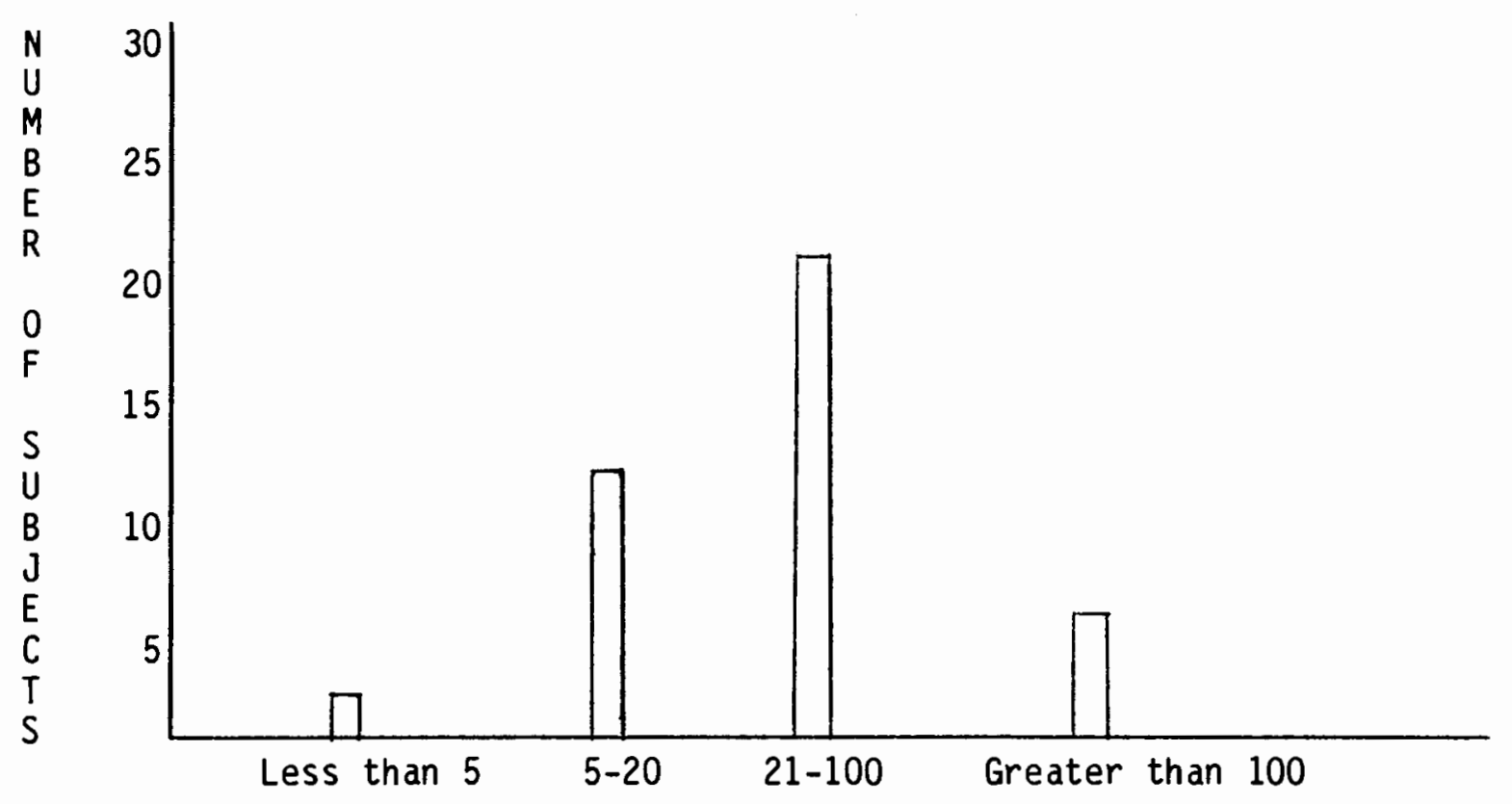

FIGURE 3. Total number of voice disordered patients seen per year as reported by respondents.

Population Served by Subjects

Of the total 41 respondents to this study, the greatest number, 11 (27\%) practiced in an area with a population of 25-50,000 people. Nine subjects (22\%) served a population area of $250-1,000,000$ people, and 8 subjects (20\%) served an area of 100-250,000 people. Seven subjects (17\%) served areas of over 1 million people. Five subjects (12\%) practiced in areas of 50-100,000 people and 1 subject (2\%) served an area of less than 25,000 people (see Figure 4). 


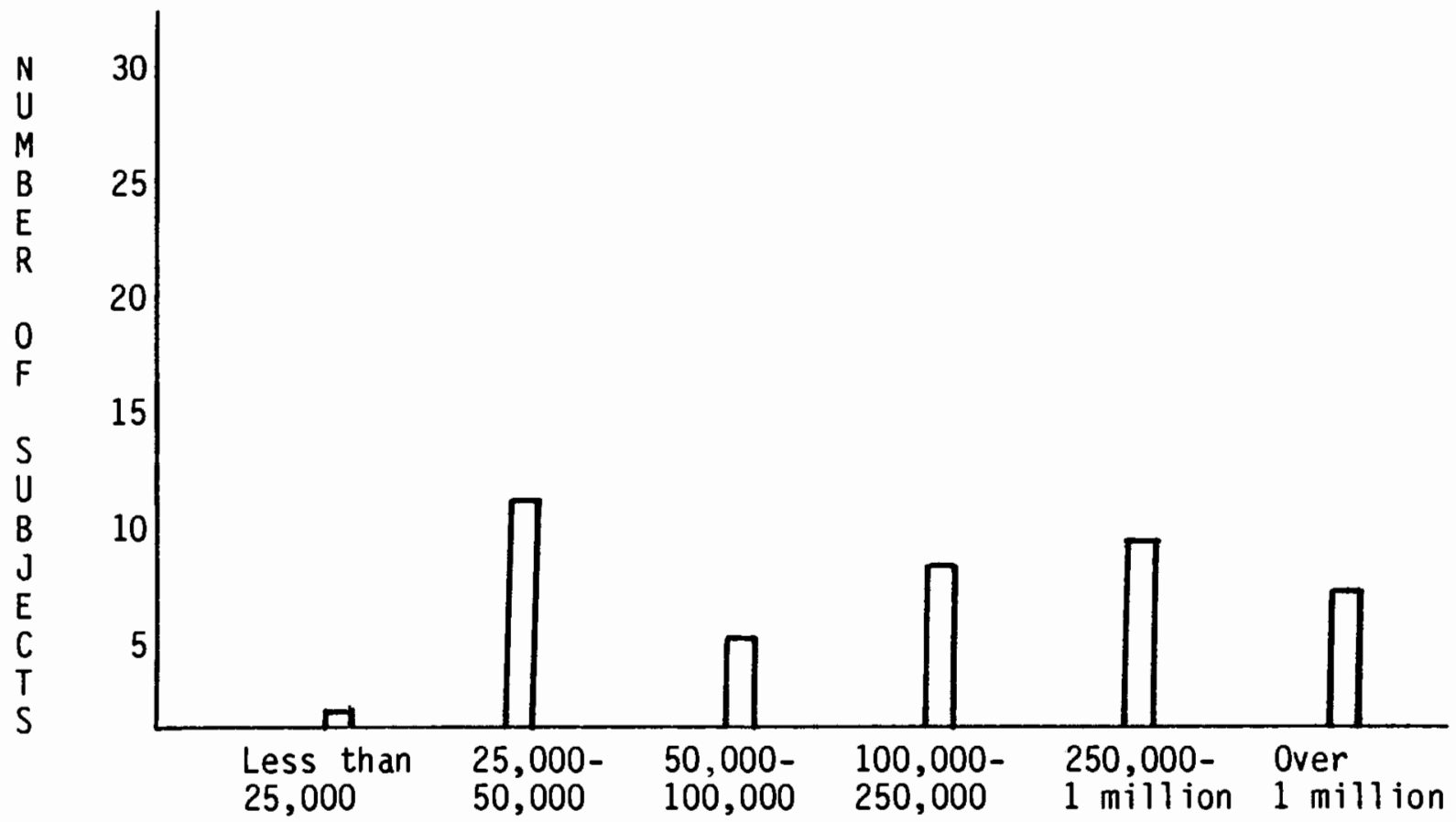

FIGURE 4. Population size of area served by respondents.

of the 18 respondents from the state of Washington, 9 subjects (50\%) practiced in the King County area. Two subjects (11\%) practiced in each the $\mathrm{Cl}$ ark County and Spokane areas. One subject (6\% each) practiced in the following counties: Pierce, Yakima, Chelan, Whatcom, and Gray's Harbor.

The greatest amount of the 18 subjects from oregon practiced in Multnomah County ( 6 subjects $-33 \%$ ). Three respondents (17\%) reported practicing in Linn County. Two respondents (one of which also served Multnomah County) practiced in Washington County (11\% each). One subject (6\% each) practiced in the following counties: Yamhill, Benton, Lane, Joseph, Klamath, Union, Clackamas, and Jackson .

Two of the five subjects (40\%) from Nevada practiced in Washoe County. One subject (20\% each) practiced in Las Vegas, $\mathrm{Cl}$ ark, and Carson City Counties. 
Education of Subjects and Exposure to Speech Pathology

Subjects in this study were asked the location and date of their medical degree training (nonspecialty training), residency training, surgery training, and research training (all three phases included as specialty training). Subjects al so were asked to report their exposure to speech pathology in each of the training settings.

Medical degree. A wide variety of locations were listed for medical degree training as with each training phase. Of the 40 subjects who named the location of their medical degree training, 7 (18\%) attended the University of Oregon, $5(13 \%)$ attended the University of Washington, and 3 subjects (8\%) attended Marquette University. Two subjects (5\%) each attended the University of Nebraska, the University of Minnesota, the University of Iowa, and the University of Virginia. One respondent (2\% each) attended the following universities for their medical degree: Loyola, the University of California at Fresno, the University of North Carolina, the University of Colorado, the University of Ohio, the University of Alabama, the University of South Africa, the Medical College of Pennsylvania, Stanford University, the University of Indiana, the University of Illinois, the University of Florida at Gainesville, the University of Kansas, the University of Michigan, the University of Southern California, and Northwestern University.

Of the 40 subjects who listed the date of their medical degree training, 14 (35\%) had their training from 1951-60, 16 subjects (35\%) from 1961-70, and 12 (30\%) from 1971-80 (see Figure 5). 
$\square$ Respondents who did NOT receive exposure to speech pathology during medical degree (nonspecialty) training

Respondents who did receive exposure to speech pathology during medical degree (nonspecialty) training.

$\Delta$ Respondents who did NOT receive exposure to speech pathology during speciality training.

$\$$ Respondents who did receive exposure to speech pathology during specialty training.

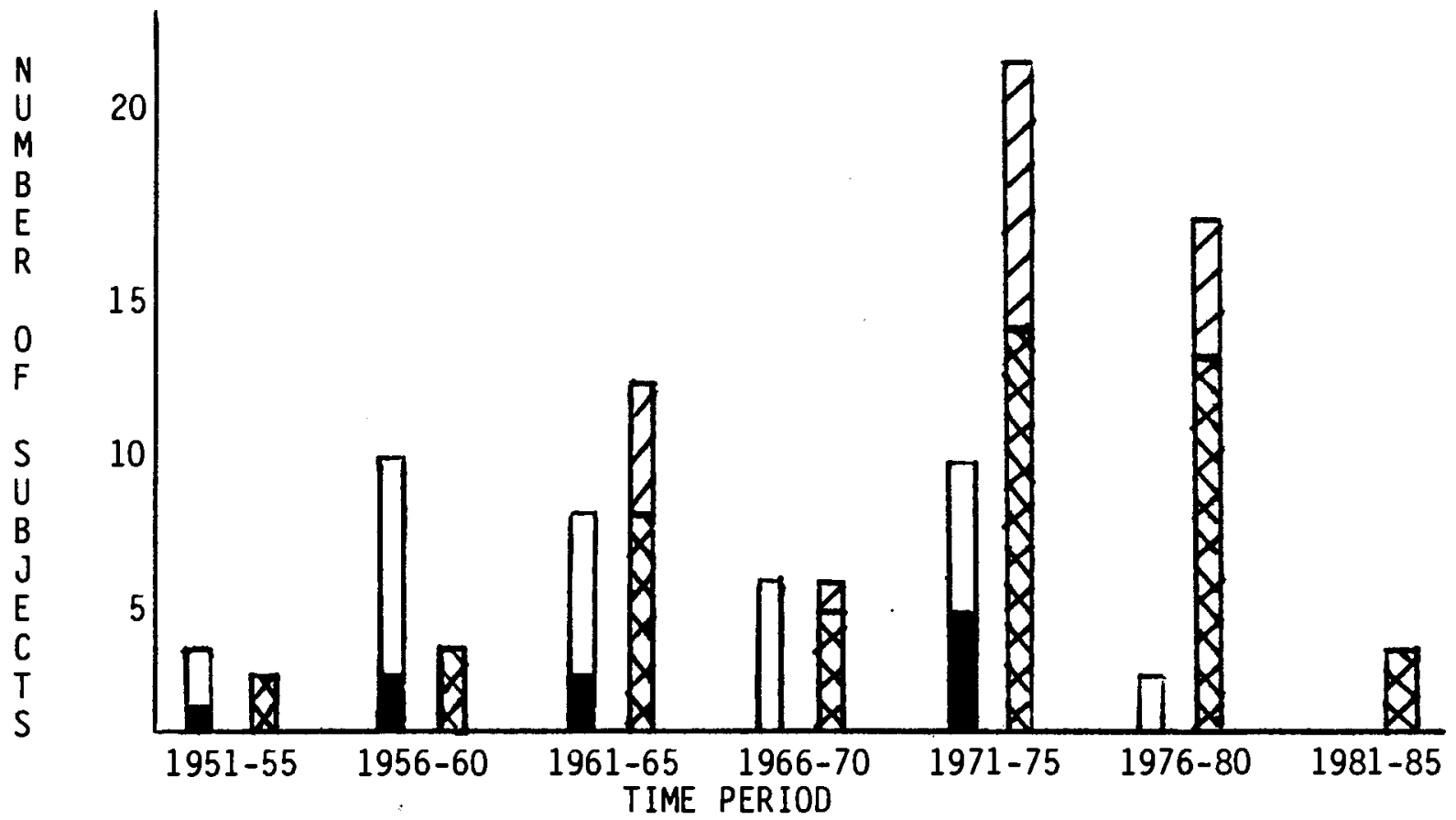

FIGURE 5. Respondents acquiring their medical degree training (first column) and post medical degree (specialty) training (second column) during specific time periods 1951 to the present

The majority of the 40 subjects who noted availability of speech pathology exposure in medical degree training reported having no such exposure (30 subjects-75\%) (see Figure 5 ). 
The percentage of subjects who did receive exposure to speech pathology in their medical degree training was 23\% ( 3 of 13 subjects who reported this information) in the 1950 's, $14 \%$ ( 2 of 14 subjects) in the 1960's, and 42\% (5 of 12 subjects) in the period from 1971-80 (see Figure $5)$.

Residency. Thirty-nine subjects named the location of their residency training. As with medical degree training, many of the subjects (6 subjects-15\%) attended the University of Oregon and the University of Washington ( 5 subjects-13\%). Three subjects each (8\%) attended the United States Naval Hospital in Oakl and and the University of Iowa. Two subjects each (5\%) took their residency at the University of Minnesota, the University of California at San Francisco, and Stanford University. One subject each (3\%) attended the following residency training programs: Johns Hopkins, the University of West Virginia, Texas, Alabama, the University of South Africa, Yale, Onio, the University of Oklahoma the United States Air Force Hospital in Texas, the University of Colorado, the United States Naval Hospital in San Diego, Wayne State University in Detroit, the University of Kansas, the University of Illinois, the Chicago Eye and Ear Hospital, and New York City Hospital.

Al1 41 respondents listed the date of their residency training. Three subjects (7\%) took their residency in the period from 1951-60. Fourteen subjects (34\%) had their residency training from 1961-70. Twenty-two subjects (54\%) received residency training in the 1970's and 2 subjects (5\%) did residency from 1981 to the present (see Figure 5). Of the 40 subjects who addressed the question of exposure to speech 
pathology in residency training, a majority (37 subjects-93\%) did have this exposure (see Figure 5). The percentage of subjects who did receive this exposure to speech pathology during residency training was 100\% ( 3 of 3 subjects) in the period from 1951-60, 92\% (12 of 13 subjects who reported this information) in the 1960 's, $95 \%$ (21 of 22 subjects) in the 1970's, and 100\% (2 of 2 subjects) in the period from 1981 to the present (see Figure 5).

Surgery. Twenty-five subjects named the location of surgery training. Four subjects (16\%) were trained in surgery at the University of Oregon. Two subjects each (8\%) received their surgery training at the University of Washington, the United States Naval Hospital at Oakland, the University of Minnesota, and the University of Iowa. One subject each (4\%) took their surgery training at the following locations: Wisconsin, the United States Naval Hospital at San Diego, Wayne State University at Detroit, the University of Arizona, the University of California at San Diego, Ohio, Stanford University, Yale, the University of South Africa, Alabama, the University of West Virginia, the University of California at San Francisco, and Johns Hopkins.

Twenty-three respondents listed the date of their training in surgery. Three subjects (13\%) took surgery training from 1951-60. Six subjects (26\%) were trained for surgery from 1961-70 and fourteen of the respondents (61\%) had surgery training in the 1970's (see figure 5).

of the 19 subjects who noted the availability of exposure to speech pathology during surgery training, 14 (74\%) did not receive any exposure 
(see Figure 5). The percentage of subjects who did receive exposure to speech pathology in surgery training was $100 \%$ ( 2 of 2 subjects) in the period from 1951-60, 25\% (1 of 4 subjects who reported this information) in the 1960 's and $27 \%$ ( 3 of 11 subjects who reported this information) during the period from 1971-80 (see Figure 5).

Research. Nine subjects named the location of research training. Two of these (22\%) did research at the University of Washington. One subject each (11\%) did research at the following locations: the University of Nevada, the University of Minnesota, Kresge, Alabama, the University of Iowa, the University of California at San Francisco, and the University of Oklahoma.

Seven respondents listed the date of their training in research. One subject (14\%) did research in the 1960's. Five subjects (71\%) did research in the period from 1981 to the present (see Figure 5).

Eight respondents reported the availability of speech pathology exposure during research training. Of these subjects 5 (63\%) did receive exposure to speech pathology during research training (see figure 5). The percentage of subjects who did receive exposure to speech pathology in research training was $0 \%$ ( 0 of 1 subject) in the 1960's, 60\% ( 3 of 5 subjects) in the period from 1971-80, and 100\% (1 of 1 subject) in the period from 1981 to the present (see Figure 5).

Education in speech pathology. Subjects were asked to report if they had ever received any education in speech pathology and whether that education was currently available in their community. Of 40 respondents who answered this question, $25(63 \%)$ reported having had no education in 
speech pathology. Twenty-seven subjects (68\%) noted that speech pathology education is available in their community, 5 (13\%) did not know whether speech pathology education was available, and 8 subjects (20\%) reported that speech pathology education was not available in their community. Subjects listed Otolaryngology Association Academy courses and university training as being the source of their education in speech pathology.

\section{Subjects Contact with Speech Pathologists}

Referrals Made to Speech Pathologists

All 41 respondents (100\%) reported having made a referral to a speech pathologist. The approximate number of referrals made to a speech pathologist per year ranged from 3 patients to 50 or more patients, with the average being 22 per year (see Figure 6). Most subjects (63\%) prefer not to use the same speech pathologist each time they make a referral. 


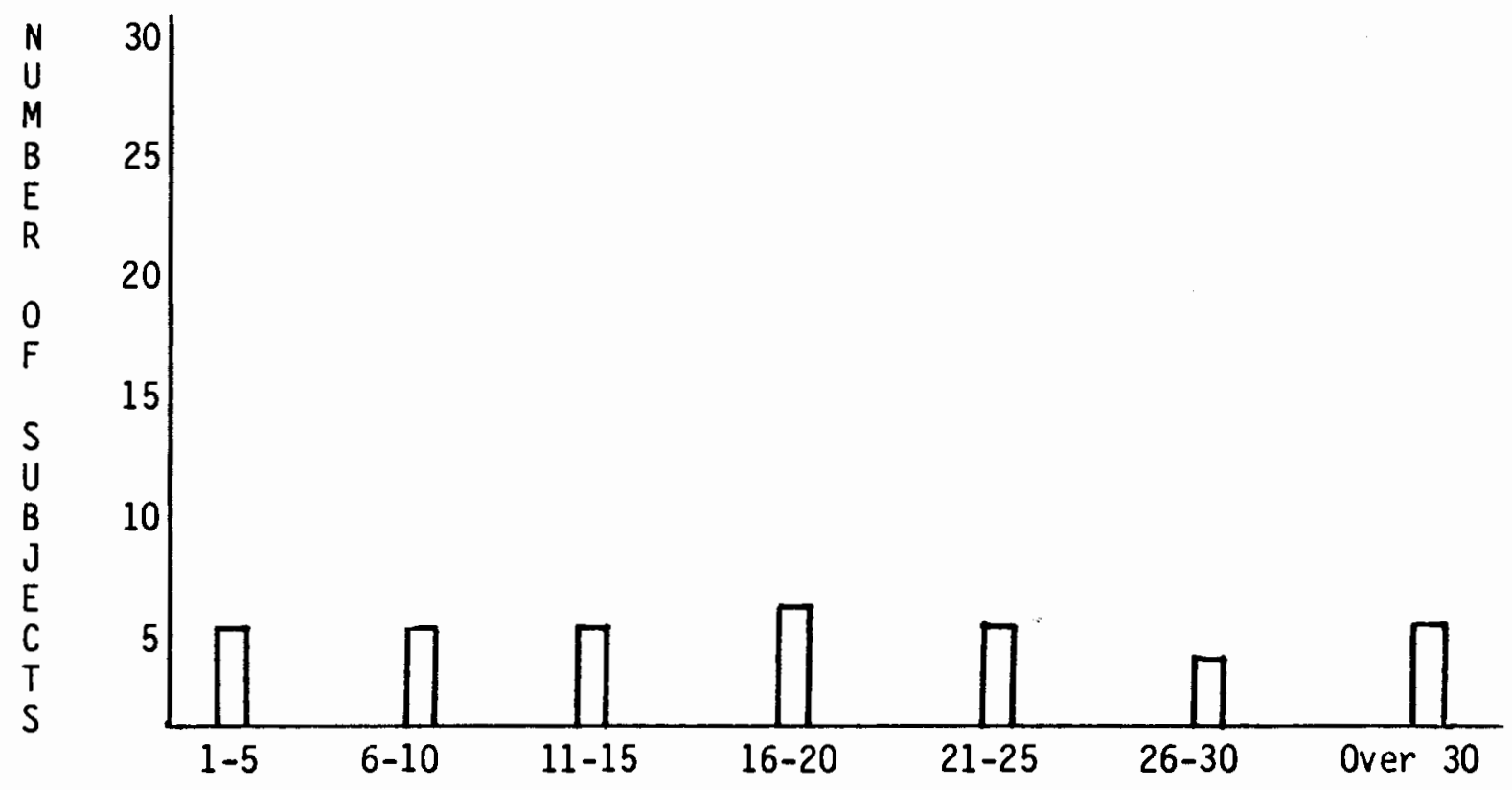

FIGURE 6. Number of total referrals made to speech pathologists per year by respondents.

Thirty-seven subjects listed disorders for which they generally make referrals to speech pathologists. Most referrals (32 subjects-86\%) made are for vocal nodules. Seventeen subjects (46\%) made referrals for abuse/fatigue/strain. Eight subjects (22\%) made referrals for functional dysphonia, seven subjects (19\%) for spastic dysphonia, 4 subjects (11\%) for paralysis, 3 subjects (8\%) for polyps, 2 subjects (5\%) for velopharyngeal incompetence, and one subject each (3\%) made referrals for polypoid degeneration, granuloma, pitch deviations, and swallowing disorders (see Figure 7). 


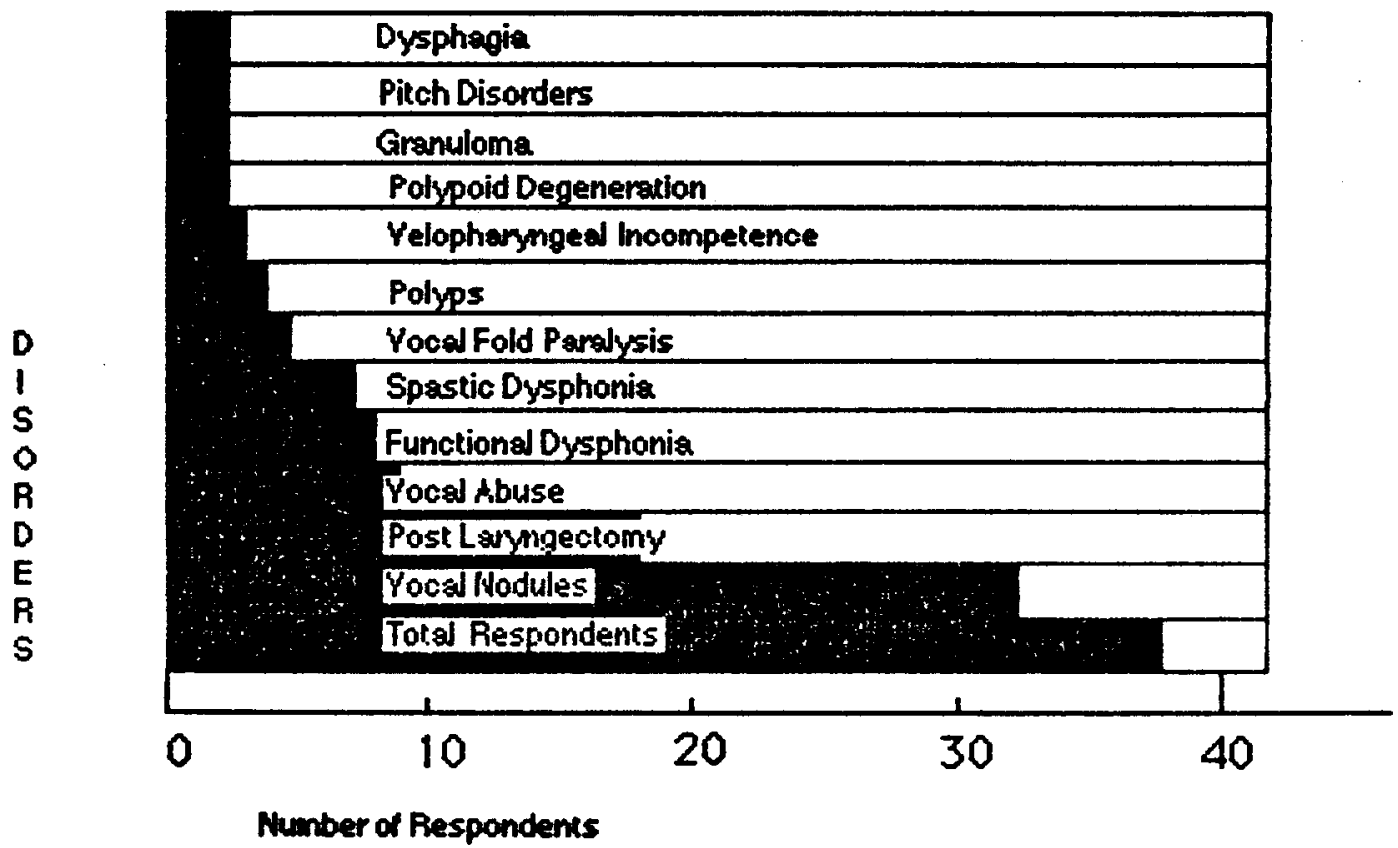

FIGURE 7. Disorders for which respondents noted as appropriate for speech pathology intervention.

Referrals Received from Speech Pathologists

Thirty-six subjects (88\%) reported having received referrals from a speech pathologist. The approximate number of referrals received from speech pathologists per year ranged from 1 patient to 30 patients per year, with the average being 15 patients per year (see Figure 8). Of thirty-four subjects who noted the disorders for which they typically received a referral, 100\% listed chronic hoarseness (possible vocal nodules). Four subjects (12\%) al so listed palatal dysfunctions and one subject (3\%) noted swallowing problems. 


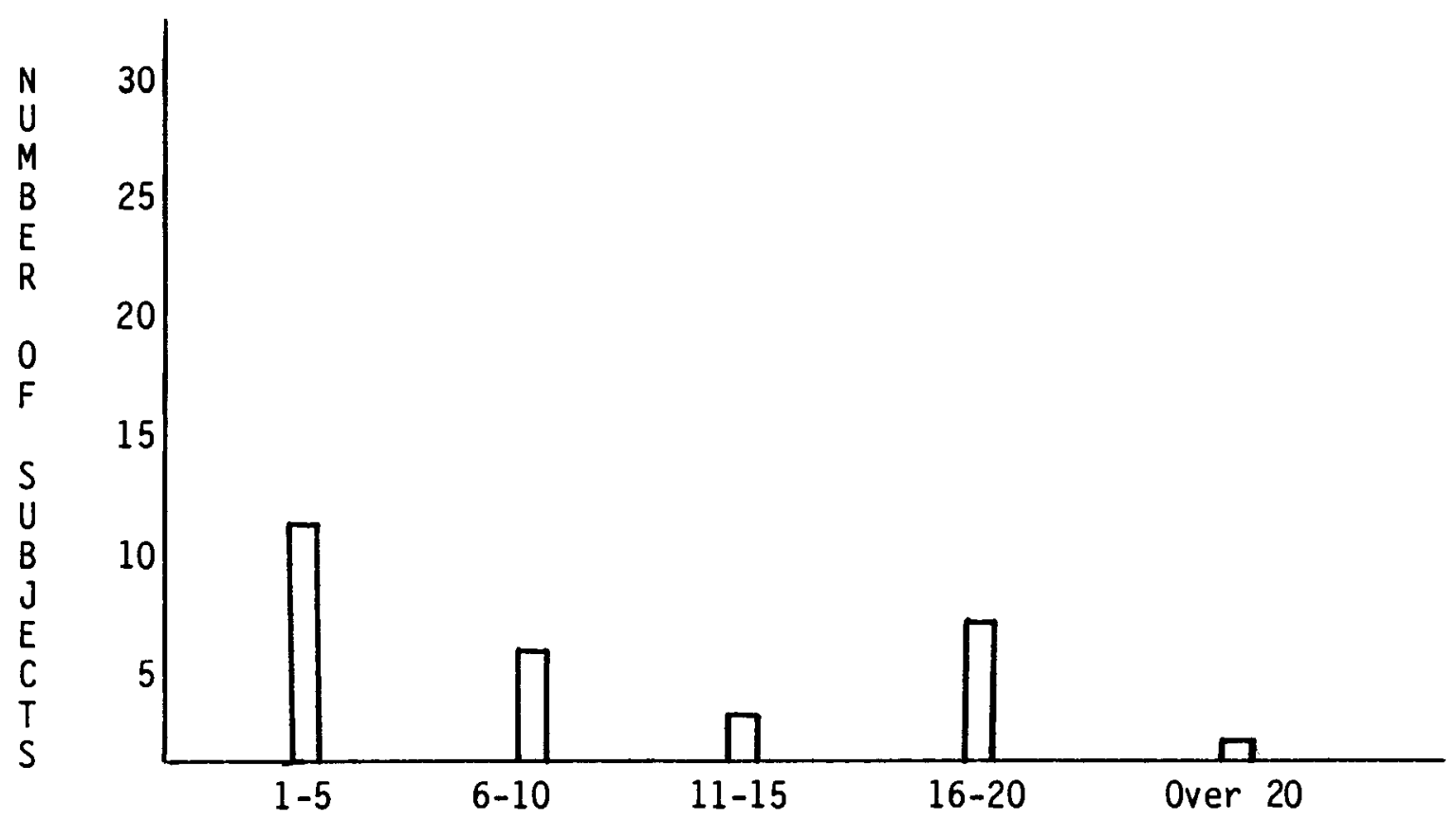

FIGURE 8. Total number of referrals received from speech pathologists by respondents.

Direct Contact with Speech Pathologists

Subjects were asked to report the amount of direct contact they have with speech pathologists (including phone calls). The greatest percentage of respondents (19 subjects-46\%) reported direct contact with speech pathologists more than once per month. Twenty percent ( 8 subjects) reported contact once per month, 27\% (11 subjects) have contact once every few months, and $7 \%$ ( 3 subjects) have contact with speech pathologists less than once per year (see Figure 9). 


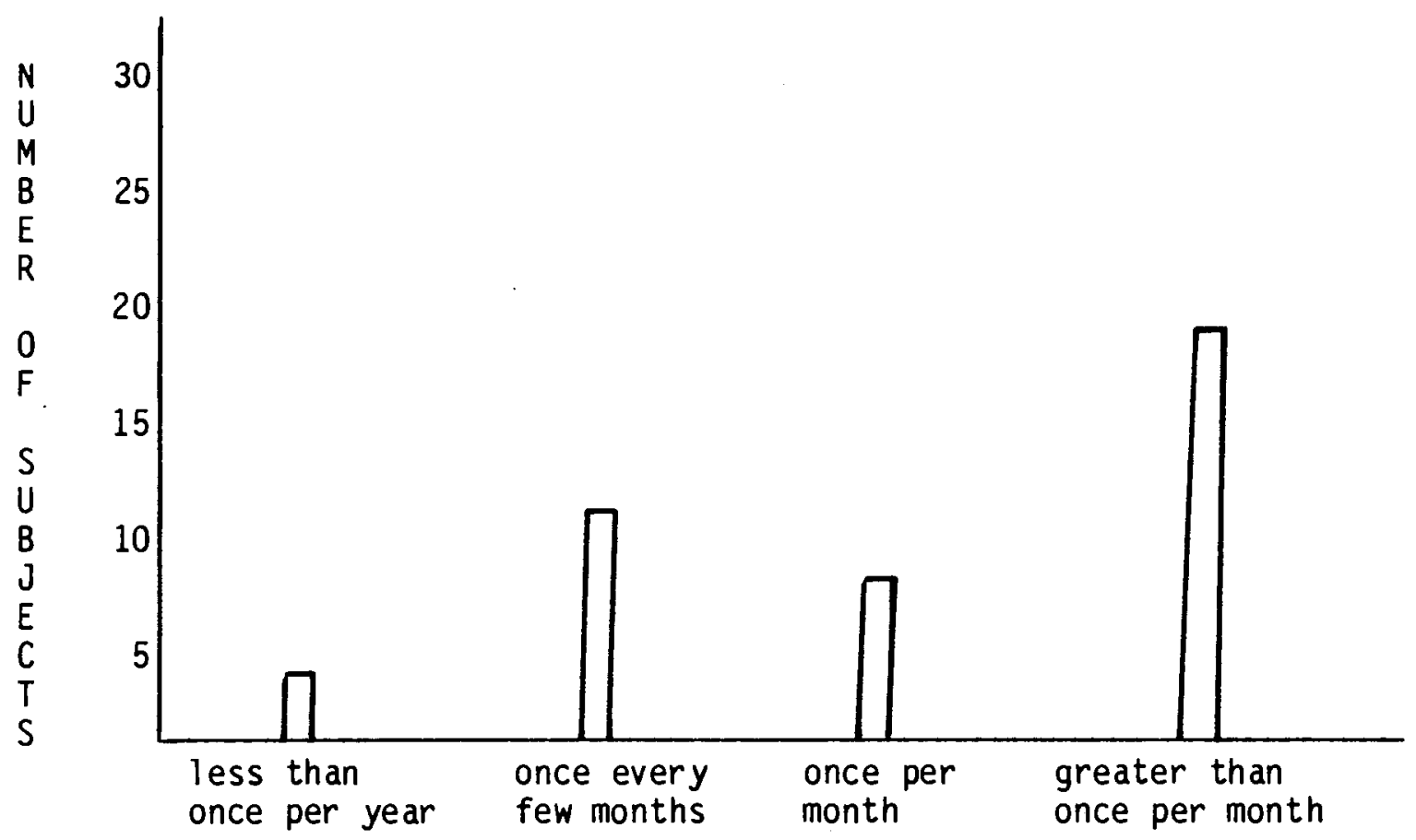

FIGURE 9. Respondents' contact with speech pathologists (including phone calls).

Subject Knowledge about Speech Pathologists

Knowledge of Speech Pathologists' Education

Subjects were asked to report what they bel ieved to be the level of a speech pathologist's education. The greatest number of subjects ( 31 subjects-76\%) marked Master's Degree. Eight subjects (20\%) believed speech pathologists to have Bachelor's Degree and two subjects (5\%) had no knowledge of a speech pathologist's education level (see Figure 10). 


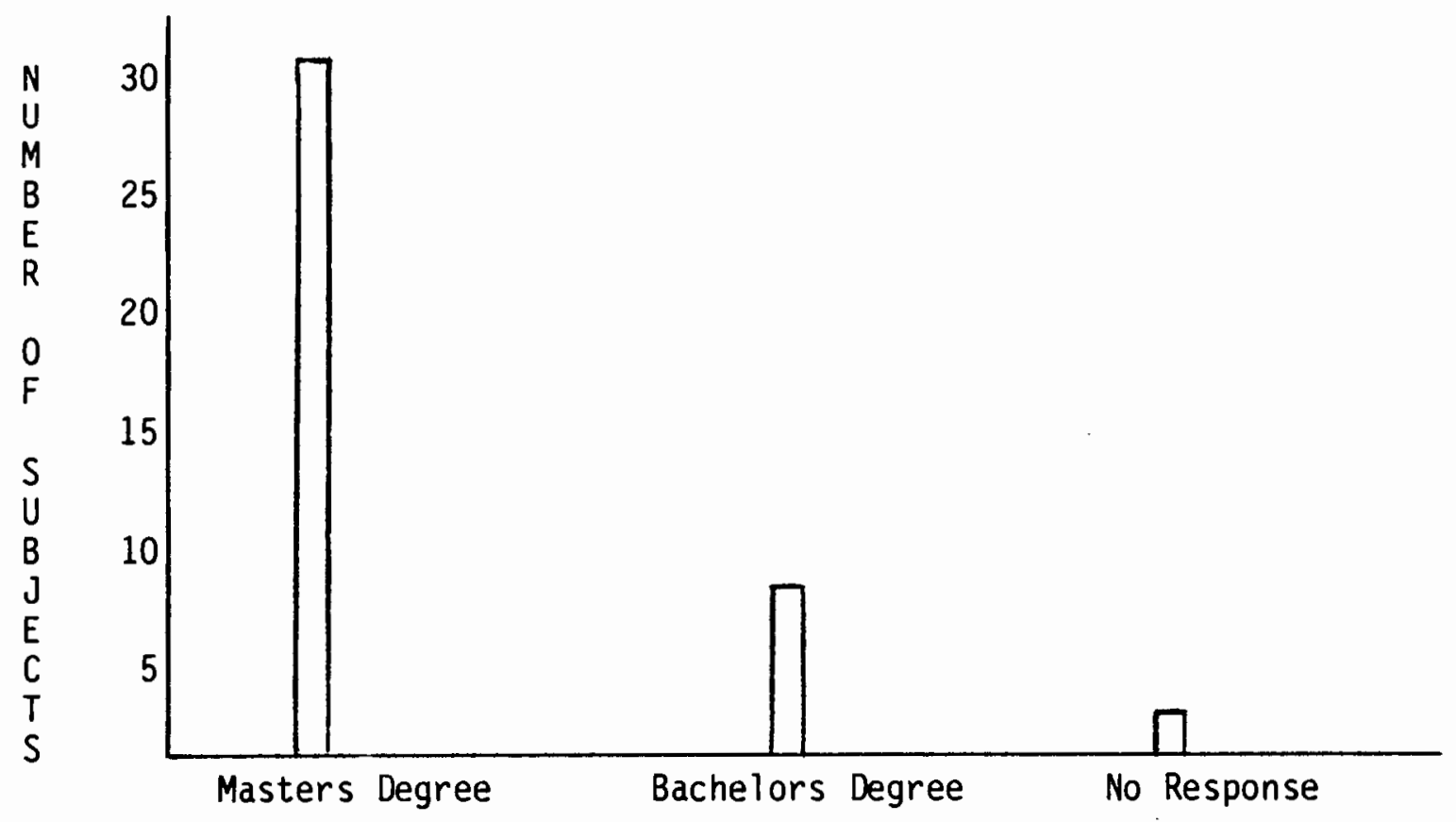

FIGURE 10. Respondents' knowledge of the educational level of speech pathologists.

Knowledge of Requirements for Certificate of Clinical Competence

Subjects were also asked what they bel ieved to be the requirements for certification by the American Speech-Language-Hearing Association. Sixty-six percent (27 subjects) believed a national examination to be a requirement for certification. Forty-one percent (17 subjects) noted 300 hours of direct contact to be a requirement. Seventy-one percent (29 subjects) noted a Master's Degree as being a requirement and 39\% (16 subjects) checked a Clinical Fellowship Year. Two of the subjects (5\%) did not check any of the given requirements for certification and none of the subjects checked all 4 of the requirements for certification by the American Speech-Language-Hearing Association (see Figure 11). 


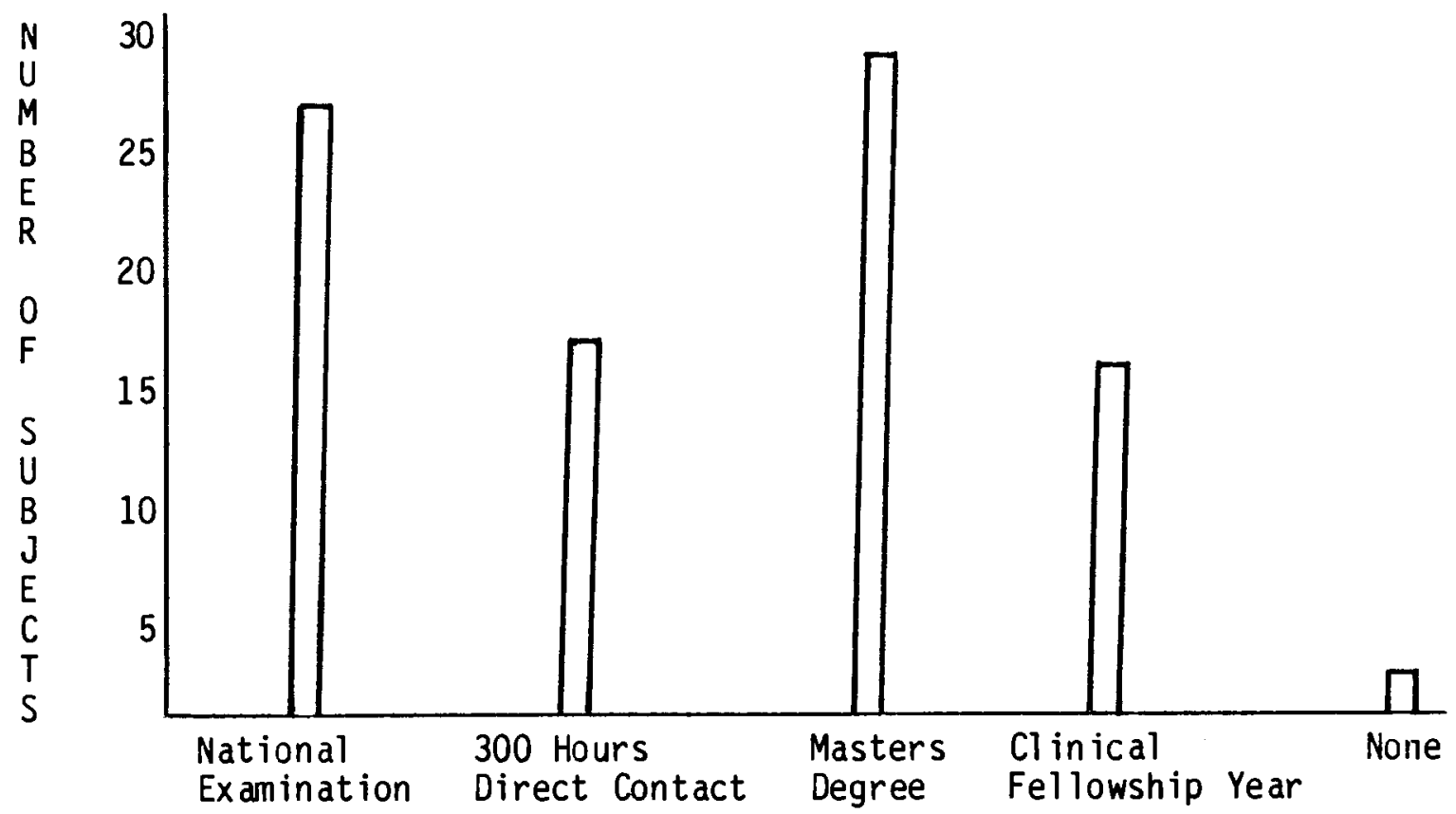

FIGURE 11. Respondents knowledge of the requirements for the Certificate of $\mathrm{Cl}$ inical Competence.

Voice Disorders with which Speech Pathologists are Helpful

Subjects were asked to mark specific voice disorders with which speech pathologists are most helpful. Ninety-five percent (39 subjects) believed speech pathologists to be helpful with development of voice after laryngectomy. Eighty percent ( 33 subjects) marked rehabilitation of voice after surgical management of tumors such as papilloma, polyps, or cysts. Seventy-eight percent ( 32 subjects) found speech pathologists helpful with rehabilitation for 1 aryngeal trauma. Sixty-eight percent (28 subjects) checked vocal restoration for unilateral vocal fold paralysis with teflon implant. Eighty-eight percent ( 36 subjects) believed speech pathologists helpful with vocal disorders with no apparent pathology. Ninety-three percent ( 38 subjects) marked management of vocal nodules before and as an 
alternative to surgery, and $83 \%$ (34 subjects) found speech pathologists appropriate in the management of contact uicers before and as an al ternative to surgery (see Figure 12).

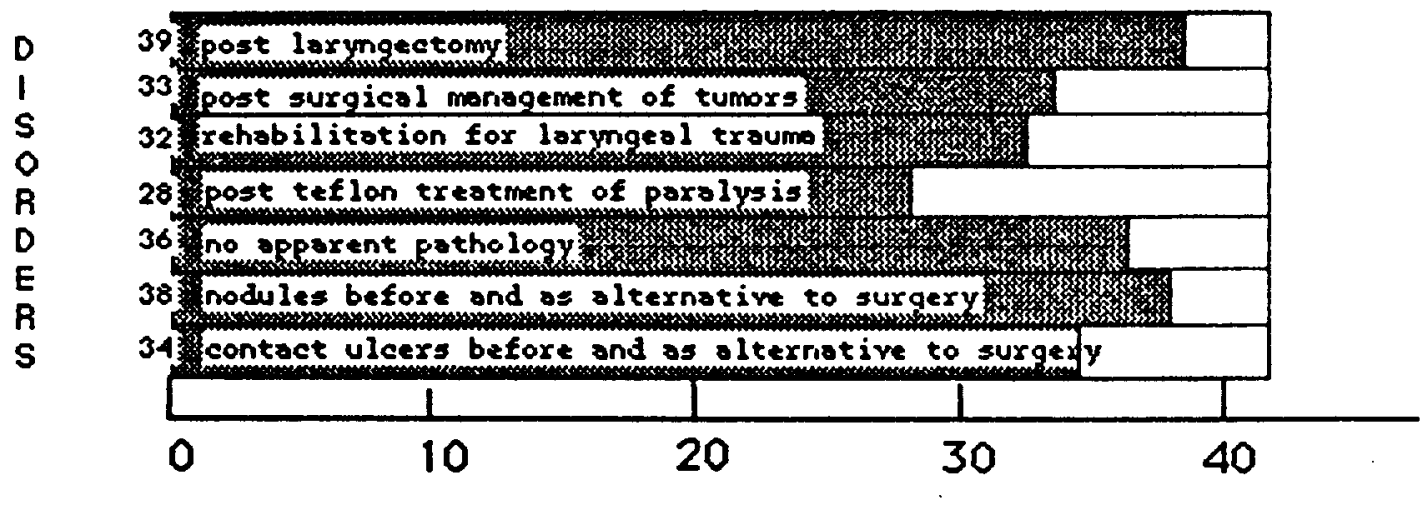

Nember of Respondents

FIGURE 12. Voice disorders for which respondents view speech pathologists helpful.

\section{Textbooks Influencing Subjects' Knowledge}

When subjects were asked to list textbooks which influenced their knowledge about speech pathologists, most listed "none" (17\%, 7 subjects) or did not respond at all $(63 \%, 26$ subjects). Those textbooks which were listed were: Coats and Shenk five volume text of Otolaryngology, Perkins, Balcenger, Lederer, Boone, DeWeese, Brodnitz, and "general ENT literature."

\section{Subjects' Reaction to Position Statements}

Subjects were asked to respond to a number of position statements (seven drawn from the literature and one drawn from personal interview). They circled a number from one to seven as to whether they agreed or disagreed with the given statement. The following statements are presented 
in the order they appeared on the questionnaire. Each statement is followed by the distribution of the responses to that statement. Speech pathologists should be supervised by a physician for diagnosis of voice problems

Of thirty-seven subjects who responded to this question, the majority (22 subjects-59\%) "strongly agreed" with the statement. In addition to the thirty-seven respondents, four subjects refused to answer this question for the following reasons: "wrong question," "ambiguous and unclear," or "too broad a question." of the twenty-two subjects who "strongly agreed" with the statement, one revised the given statement to read "work with" rather than supervise, one appended "in concert," and another added "examination at least" (see Figure 13).

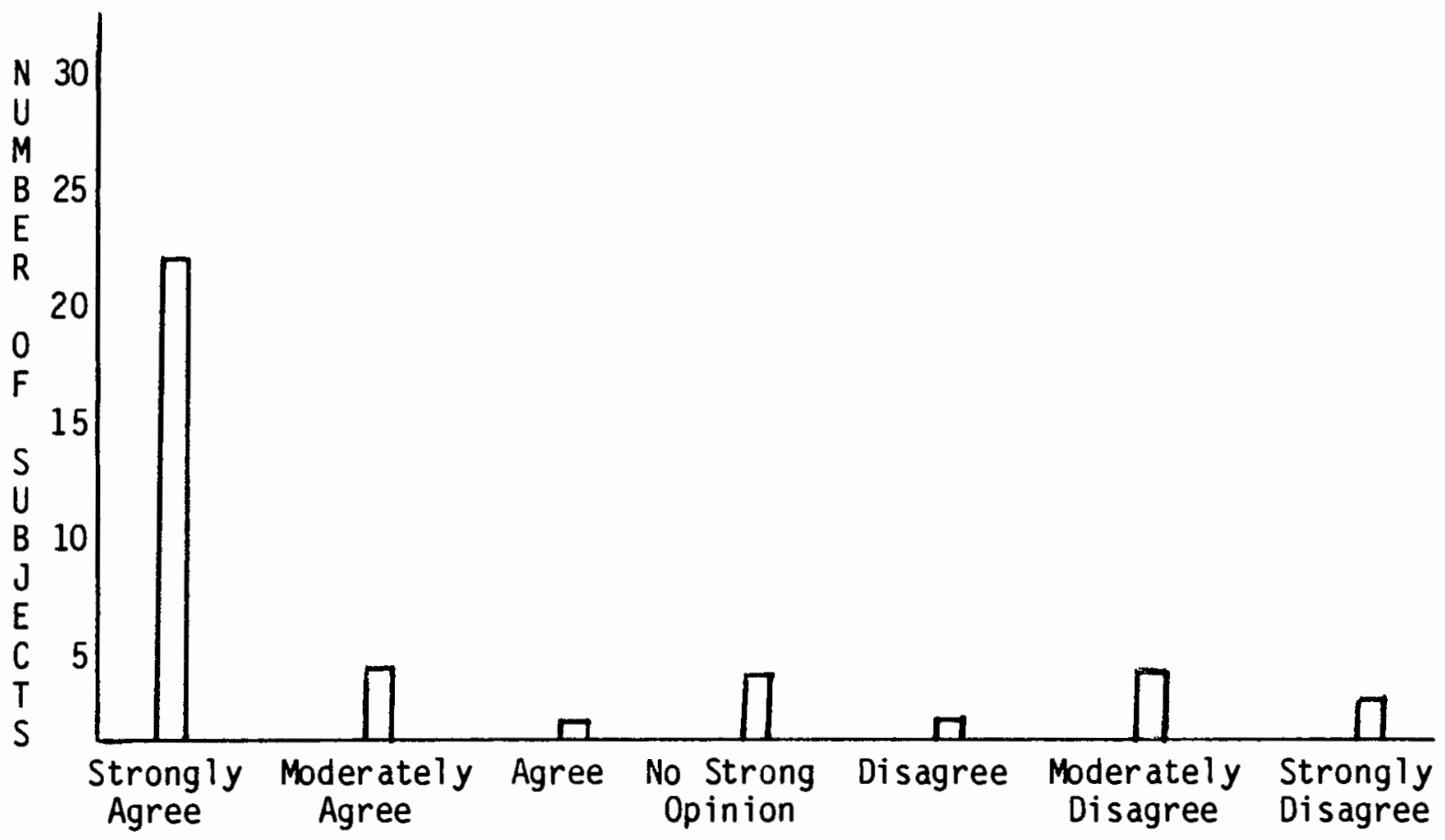

FIGURE 13. Respondents' reactions to statement 1: speech pathologists should be supervised by a physician for diagnosis of voice problems. 
Speech pathologists should be supervised for voice management by a physician

Thirty-seven subjects also responded to this question, al though the direction of the responses was not as clear as in the question above. The majority (12 subjects-32\%) chose the most neutral of the polar responses "no strong opinion either way." Many subjects (8 subjects-22\%) chose "strongly disagree." Once again, the four subjects who refused to respond cited the same reasons as for the previous question (see Figure 14).

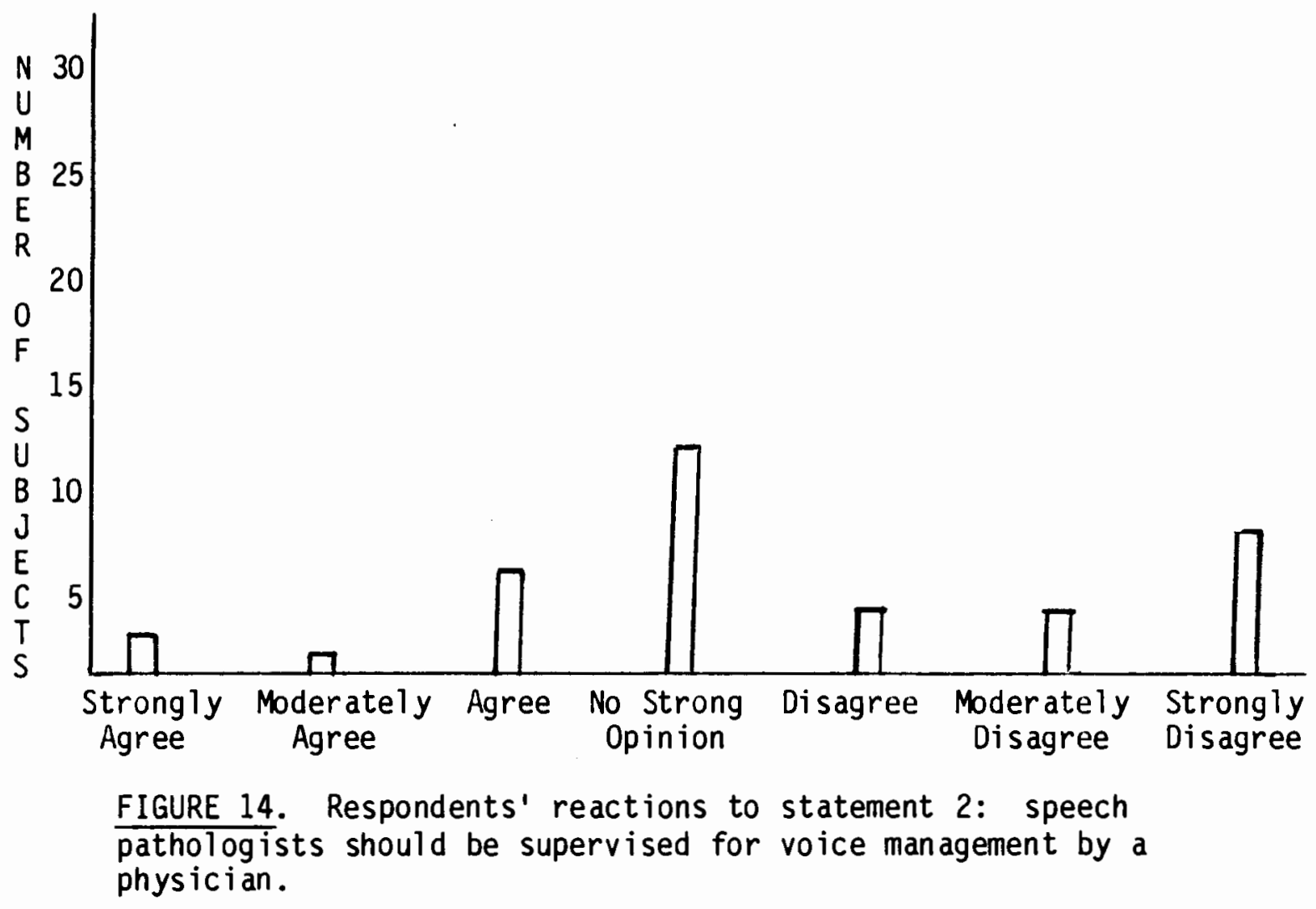

Vocal re-education by a speech pathologist is the first treatment of choice in the management of vocal nodules

The majority of the forty-one subjects who responded to this question "strongly agreed" with the statement (21 subjects-51\%) (see Figure 15.) 


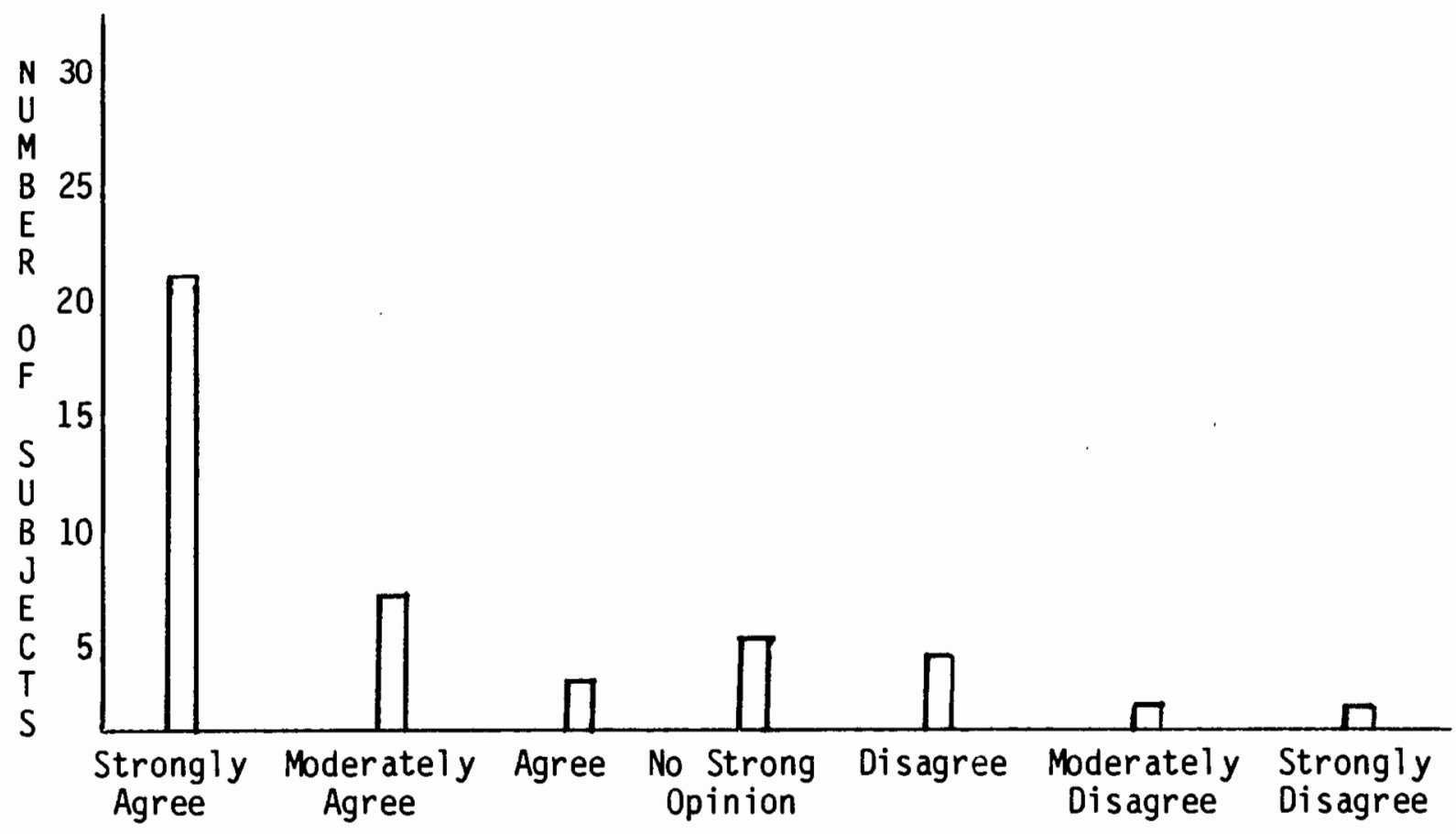

FIGURE 15. Respondents' reactions to statement 3: vocal re-education by a speech pathologist is the first treatment of choice in the management of vocal nodules.

The diagnosis of voice problems is in the domain of the otolaryngologist solely

of thirty-nine subjects who responded to this statement, the greatest amount (11 subjects-28\%) "strongly disagreed" with the statement; however, the remaining responses were widely spread across the scale. The subjects who chose not to respond noted difficulty with the term "diagnosis" in the question (see Figure 16). 


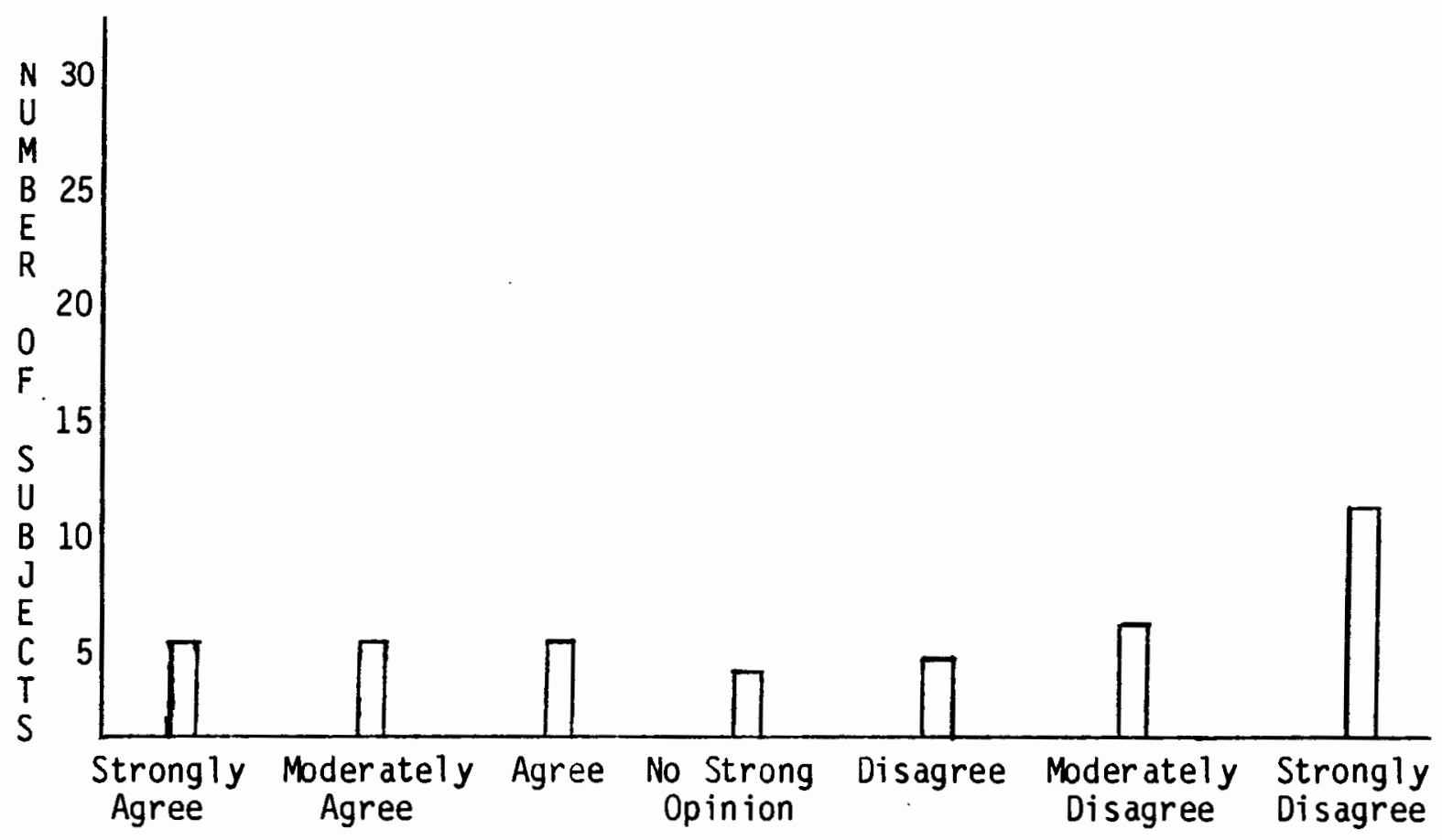

FIGURE 16. Respondents' reactions to statement 4: the diagnosis of voice problems is in the domain of the otolaryngologist solely.

When a speech pathologist consults with a physician but is not under their supervision, the speech pathologist is not operating in the best interests of the patient

The forty subjects who responded to this question tended to "strongly disagree" (12 subjects-30\%) or "moderately disagree" (14 subjects-35\%) with the statement. One subject described the question as unclear and had difficulty with the term "supervision" and chose not to answer (see Figure 17). 


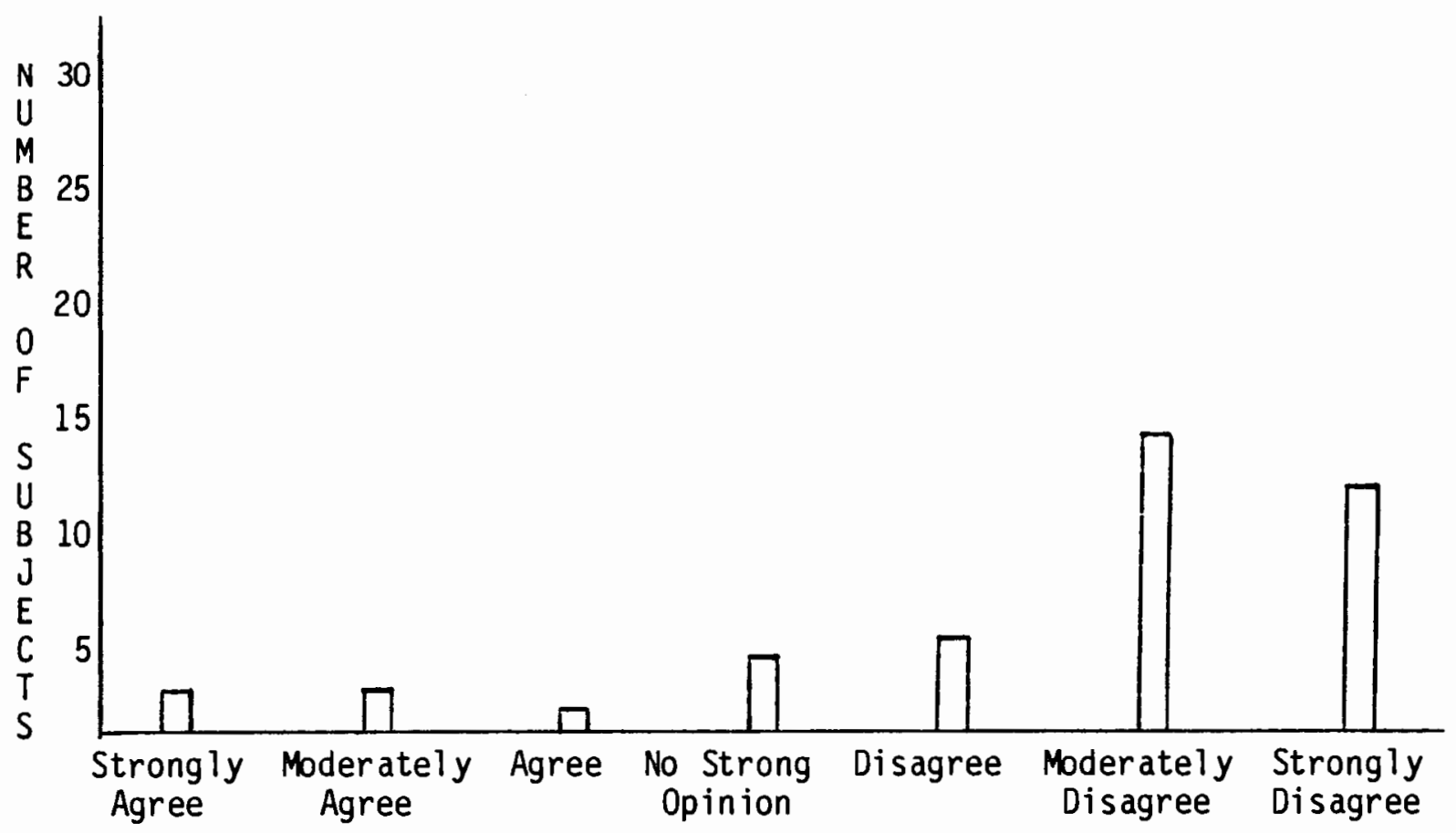

FIGURE 17. Respondents' reactions to statement 5: when a speech pathologist consults with a physician but is not under their supervision, the speech pathologist is not operating in the best interests of the patient.

The use of a speech pathologist in voice problems is unnecessary unless problems with phonation occur after surgery

The forty subjects who responded to this question also tended to "strongly disagree" (19 subjects-48\%) or "moderately disagree" (14 subjects-35\%) with the statement (see Figure 18). 


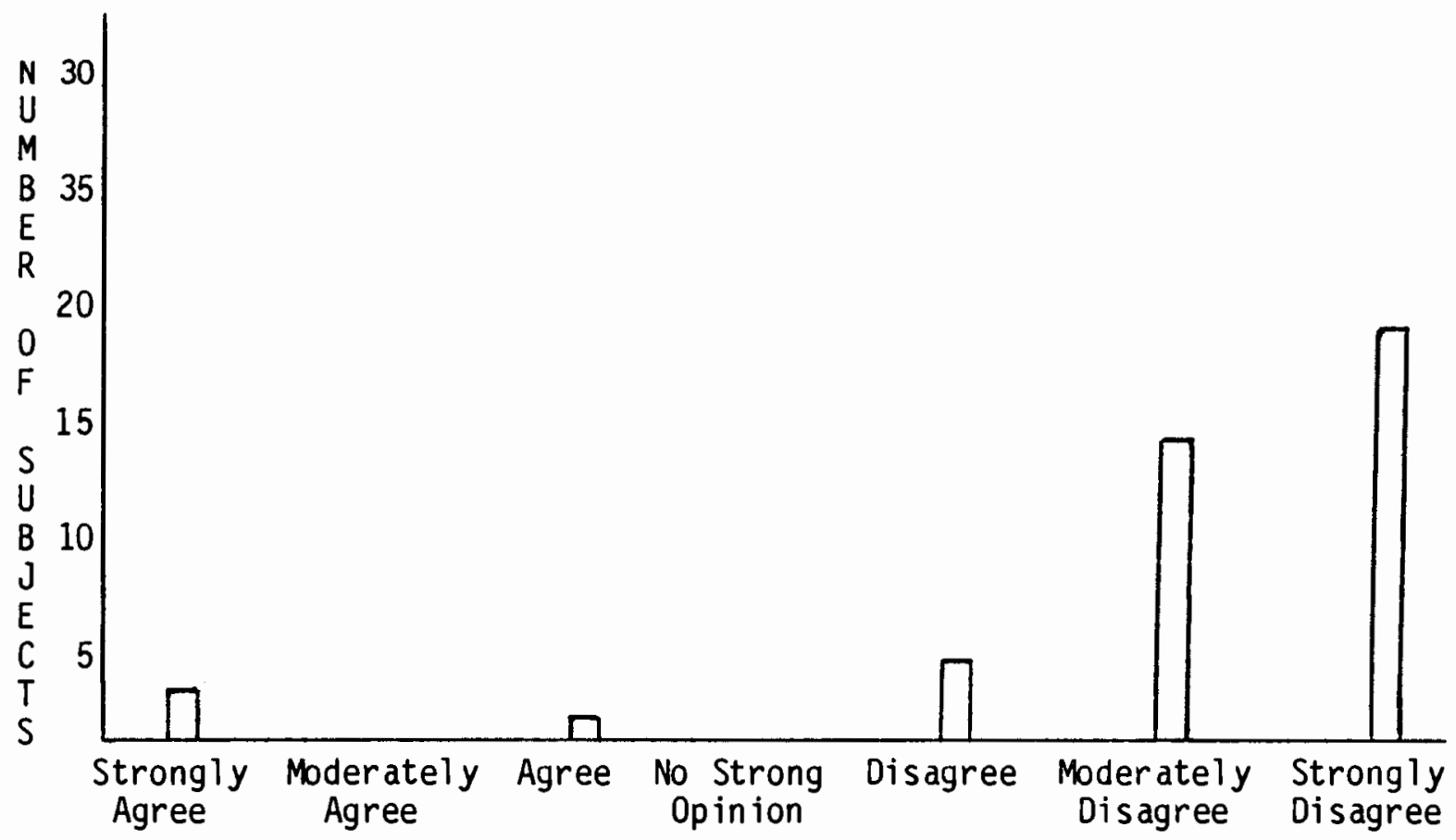

FIGURE 18. Respondents' reactions to statement 6 : the use of a speech pathologist is unnecessary unless problems with phonation occur after surgery.

Speech pathologists offer an effective alternative to some surgeries of the vocal mechanism

There was also a clear direction of the reactions to this statement. Most respondents (16 subjects-40\%) "strongly agreed" and many subjects (12 subjects-30\%) "moderately agreed" with the statement (see Figure 19). 


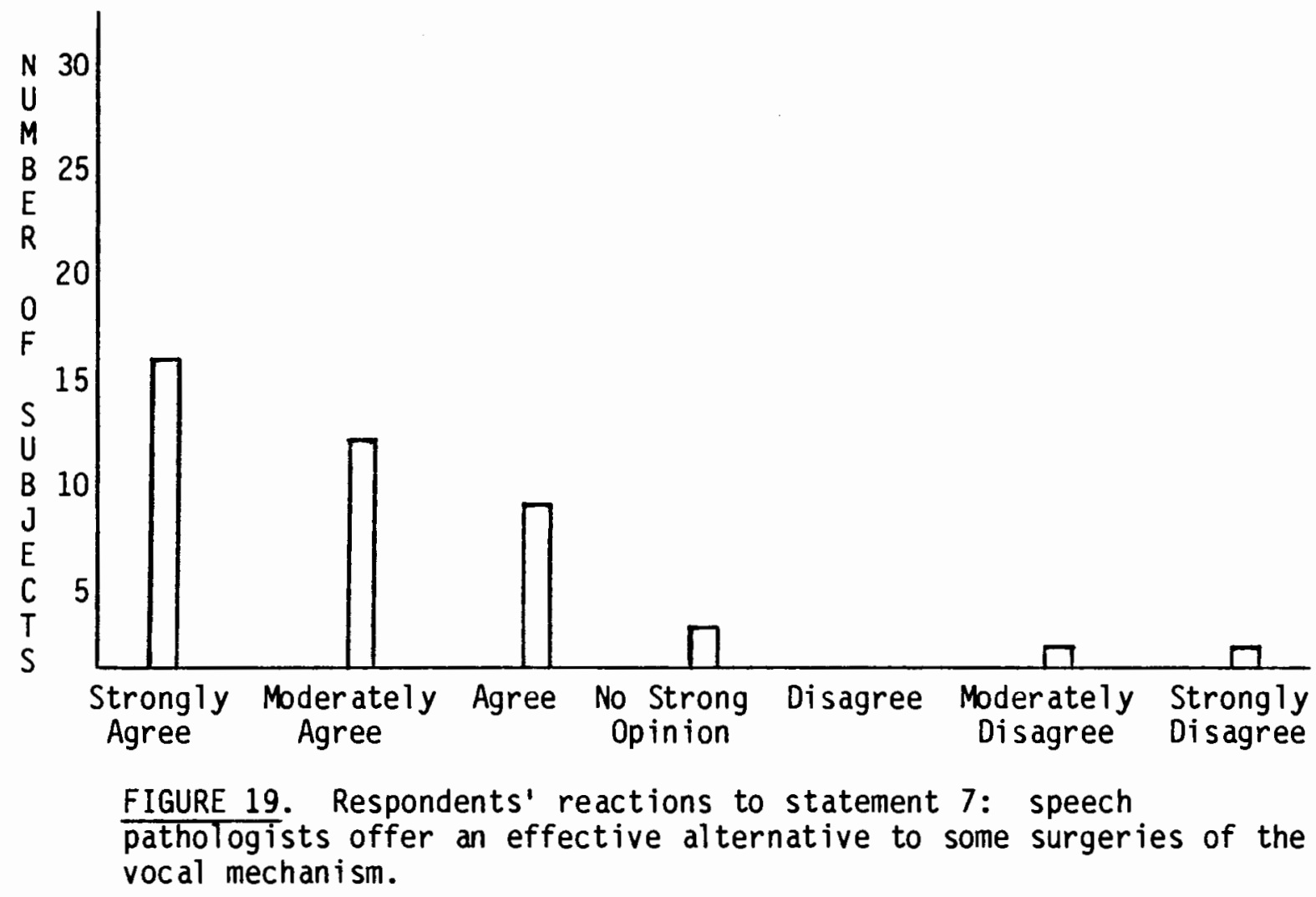

Speech pathologists I come in contact with generally teach the voice disordered patient more appropriate techniques of phonation

All forty-one subjects agreed to some degree with this statement. Eighteen subjects (45\%) "strongly agreed" and nineteen subjects (48\%) "moderately agreed" with the statement (see Figure 20). 


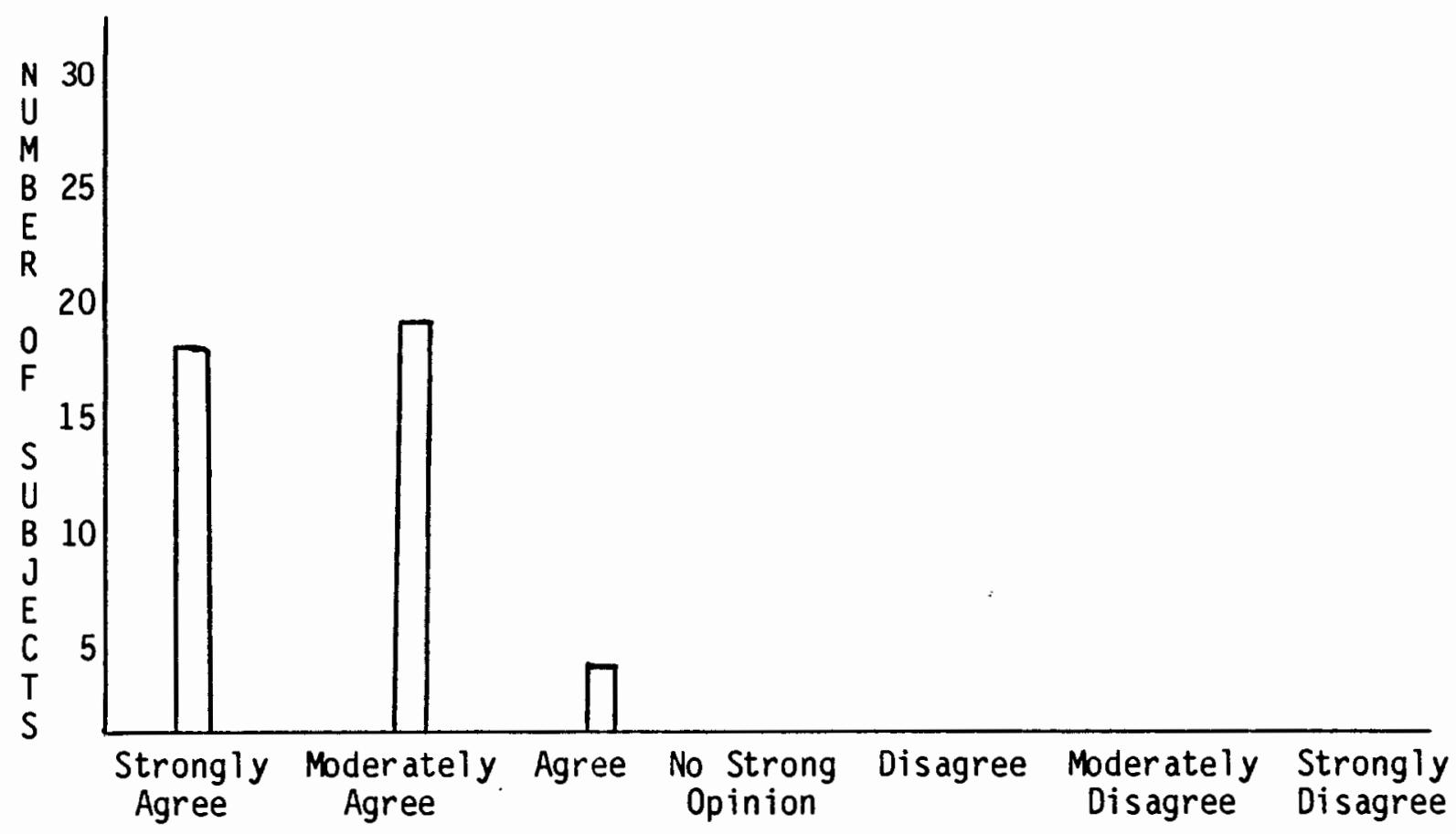

FIGURE 20. Respondents' reactions to statement 8: speech pathologists I come in contact with generally teach the voice disordered patient more appropriate techniques of phonation. 
CHAPTER $V$

\section{DISCUSSION}

As with the results chapter the following discussion will address the study questions posed at the outset of this project. The questions posed were: what exposure did the respondents have to speech pathology in their medical training experience (including a general profile of those who responded); what professional contact did the respondents have with speech pathologists in their practice; what knowledge did the respondents have of a speech pathologists' general education and specific training in voice disorders; and on a semantic differential scale, how did the subjects react to position statements drawn from opinions expressed by otolaryngologists.

\section{Profile of Respondents}

There appeared to be little significant difference in the rate of responding between the three states surveyed. This is despite the inclusion in the Nevada population of a personal invitation to participate from Stephen McFarlane, Ph.D., Speech Pathologist, at the Medical School of the University of Nevada at Reno.

Those subjects who responded generally had caseloads of greater than 200 patients per month of which twenty-one to one-hundred are voice 
disordered.

It appeared that respondents in major urban counties with universities in the area were more likely to respond to the questionnaire. However, because there are a greater number of possible subjects in the larger population areas, this conclusion may be unfounded.

The respondents acquired their training in a variety of settings. A slightly greater number of subjects attended northwest universities (i.e., Oregon Health Sciences University and the University of Washington) in each phase of training. It appeared that subjects received exposure to speech pathology in residency training (specialty training) almost exclusively (rather than medical degree/nonspecialty training), regardless of the date or location of their training. It was interesting to contrast this with the 1977 National Institute of Neurological Communication Disorders and Stroke report which found 44 percent of medical schools offering speech-language subspecialty instruction (assuming this instruction is part of medical degree training). The questions were raised as to what constitutes speech-language subspecialty instruction; was this instruction required or elective for medical students; and what did the respondents perceive the term "speech pathology exposure" to include.

While 68 percent of the subjects were aware that speech pathology education was available to them in their community, 63 percent chose not to participate in that training. Of those subjects who noted they had received training in speech pathology, one third listed receiving that training in their university courses. This brings the percentage of subjects who actually sought further education in speech pathology (in 
addition to any required) to 25 percent of the total respondents which represented a very small portion of those sent questionnaires.

\section{Professional Contact}

While all of those who responded reported they made referrals to speech pathologists for voice disorders, the amount per year varied greatly and most preferred not to use the same speech pathologist each time. Because many of these referrals were for vocal nodules and/or post laryngectomy patients, the particular speech pathologist referred to may have been indicated by the convenience of the patients (i.e., school age children with vocal nodules referred to that child's school speech pathologist and the post laryngectomy patient referred to the hospital where the laryngectomy is performed).

While all respondents made referrals to speech pathologists, 88 percent have received referrals from speech pathologists. It appears that a small percentage of the respondents were making referrals to speech pathologists and not receiving them. This observation and the lower average number of referrals made to respondents (versus the average number of referrals of respondents to speech pathologists) may perhaps affect how the respondents viewed the collaboration process.

\section{Knowledge}

While most subjects knew that speech pathologists generally have a 
masters degree, none of those responding were aware of the full requirements for a Certificate of Clinical Competence from the American Speech-Language-Hearing Association. Considering that most speech pathologists probably do not know the requirements for an otolaryngologist to be certified, this finding may seem unimportant. However, an otolaryngologist's qualifications are rarely in question, while speech pathologists seem to be often defending their position in speech-language-hearing diagnosis and remediation (as evidenced by the policy statements of the American Academy of Otolaryngology).

Generally, respondents agreed with the given list of disorders that speech pathologists are helpful with. Vocal restoration for unilateral vocal fold paralysis with teflon implant was marked by only 68 percent of the respondents, while all the other given disorders were marked by 78 percent of the respondents or more. It would have been interesting had there been foils included in the list (i.e., disorders which generally are not considered in the literature as benefiting from speech intervention such as congenital web and papilloma).

Very few respondents noted a particular textbook which they used as a resource for information about speech pathology. This may indicate little interest in this knowledge; confidence in the knowledge of speech pathologists with whom they are in contact; or that they rely upon correspondence courses and specialty articles for the information.

\section{Subjects Reaction to Position Statements}


favorable to more favorable attitudes of responding laryngologists towards speech pathologists working with voice disordered clients.

less favorable

1

$\# 4$

$\# 1$

more favorable

4

$\# 2$
$\# 5$

$\# 8$

FIGURE 21. The mode (where the greatest amount of subjects responded) of responses to each position statement (noted by statement number-\#).

In studying the above diagram, it was evident that the respondents had more favorable attitudes in all but two questions. Both of those questions dealt with the concept of "diagnosis." The term diagnosis appeared to elicit strong reactions from the medical personnel responding. It could be deduced that the laryngologists responding believe the term "diagnosis" belongs exclusively to the medical field.

Perkins (1977) was very careful to distinguish that assessment is the province of speech pathology, while diagnosis is done by the physician. Engle and Davis (1963) defined the diagnosis as the art, science, or act of recognizing disease from signs, symptoms, or laboratory data. The use of the word disease in this definition infered a purely medical function. While McFarlane et al., (1984) used the word diagnosis in describing what a 
speech pathologist is responsible for, the authors were careful to say that speech pathologists make diagnostic statements (rather than a diagnosis) about speech, voice, fluency, and language: and not about physical pathology. Boone (1977) as well, adamantly stated the primary identification of laryngeal pathology is clearly the responsibility of the laryngologist. Dickson (1974) described diagnosis as including the relating of causative factors to the presenting symptoms, except in the case of voice disorders. The diagnostic data should always include data from a laryngologist who has the primary responsibility for determining the appropriate treatment approach (Dickson, 1974). Boone (1977) clarified that the decision whether or not to provide voice therapy for the patient was made by the laryngologist, while the type of voice therapy provided was decided by the speech pathologist.

The basis of the aforementioned points of view may turn upon the use of "diagnosis" as used in the "medical model" as opposed to the term "diagnosis" as used by speech pathologists. The medical model is oriented towards the identification of disease and its eradication. Speech pathology, on the other hand, tends to be oriented toward a "process analys is model." Speech pathologists identify learning processes which create and maintain a particular disorder. Subsequently they work to assist the client in "relearning" appropriate processes. The source of the conflict might very well have been what "diagnosis" meant to the respondents and not the actual procedure that speech pathologists followed in "diagnosing" voice disorders. Millisen, in Travis (1971), pointed out that the physician's diagnostic pattern does not fit the needs of the 
speech diagnostician. The physician deals mostly with physiological processes: the identification of larngeal pathology. The speech pathologist is dealing with learning processes (behavioral analysis of speech behavior) superimposed on the more fundamental physiological ones. Perhaps if the questionnaire used in this study had clearly delineated these "diagnostic" procedures used for each professional's specific purpose, there would have been a change in the reponses made to questions dealing with "diagnosis" or at least a clearer statement as to disagreement.

When observing the assumed strong reactions of the respondents to the term "diagnosis," it became questionable as to the necessity and/or value of the use of the word "diagnosis" by speech pathologists. The greatest majority of speech pathologists are in a position where their ultimate goal is to remediate speech and 1 anguage deviations and differences. In determining the remediation process, it is necessary to describe the speech and 1 anguage behavior observed. However, in many instances, it is difficult to determine (and often inconsequential to determine) the causative factors for the observed speech and language behaviors leading to the "diagnosis." The exception is the case of voice disorders where the observed speech behaviors may be the earliest sign of life threatening physiological pathology. In these cases, the causative factors or lack of them are crucial information to the ensuing remediation. The physician is the only professional who should ascertain these causative factors in voice disorders and perhaps the only professional who needs to make a "diagnosis." 
Additionally, Lillywhite (1961) discussed "professional behavior" with a number of questions speech pathologists must ask themselves when dealing with professional workers outside the field of speech and hearing. Questions were concerning the speech pathologists feelings of resentment, intrusion, and insecurity toward other professionals who have an interest in communication disorders. It seems to become a question of to what degree we can and should adapt our "professional behavior" (including our use of specific terms such as "diagnosis") to function with other professionals (especially the medical profession). It also becomes a question of who is responsible for this change of behavior, the speech pathologist or the physician. 
CHAPTER VI

SUMMARY AND CONCLUSIONS

$\underline{\text { Summary }}$

This study was designed to collect information about the working relationship of otolaryngologists with speech pathologists who provide service to voice disordered clients.

Otolaryngologists in Oregon, Nevada, and Washington were sent questionnaires which asked for information related to the four following questions: what exposure did the respondents have to speech pathology in their medical training experience; what professional contact did the respondents have with speech pathologists in their practices; what knowledge did the respondents have of a speech pathologist's general education and specific training in voice disorders; and on a semantic differential scale, how did the respondents react to position statements drawn from opinions expressed by otolaryngologists.

Because of the overall very low rate of response to this study, it was difficult to draw many conclusions. Those who did respond varied in caseload size, practice areas, sites and dates of nonspecialty and specialty training. They tended to have a fair amount of professional contact with speech pathologists and made referrals to speech 
pathologists. The subjects who answered the questionnaire generally were unsure of the training requirements of a speech pathologist. Most agreed that speech pathology intervention was appropriate in the given list of disorders.

The respondents attitudes tended to be generally favorable to speech pathologists, except in the area of diagnosis. Whether the speech pathologist's use of the concept of diagnosis was unclear to the respondents or they firmly claimed ownership of this word was difficult to determine.

\section{Conclusions}

In concluding this project it is necessary to discuss the shortcomings of the research procedures as well as describe the possible implications for future research.

The first area of concern in this completed research was the low response rate. To deal with this several measures could have been taken. The questionnaire could have been presented at larymologist association meetings and promoted at such meetings. The enlistment of a number of otolaryngologists to assist in the preparation of the questionnaire and the subsequent use of their names in a cover letter may have increased the number of respondents.

The questionnaire itself had many flaws which may or may not have been alleviated by a test/retest reliability check and/or more extensive pilot work. Additionally, there were pieces of information gathered that proved to be of no interest or use (such as County of practice). Other 
items (such as questions about the respondents' education) needed more appropriate alternatives for answers. Some items could have been expanded (such as including foils in the list of disorders for which speech pathologists are helpful). Still other items could have been worded differently to reduce ambiguity (such as the position statements).

The analysis of the data and display of the results were descriptive; however, had there been a greater number of responses to the study, more definitive statistical procedures could have been utilized and more conclusive statistical inferences could have been drawn.

\section{Implications for Future Research}

Each of the separate research questions (as listed in the summary statement) could be addressed individually in future research.

Discussion of the exposure otolaryngologists receive to speech pathology could be approached by surveying training institutions rather than the otolaryngologists. It would be interesting to know the availability of this exposure, exactly what was included in the exposure, who was responsible for guiding this exposure, if this exposure was required by the particular training institution, and how well received the exposure was by the otolaryngologists in training.

The professional contact between otolaryngologists and speech pathologists could occur in a variety of settings for a multitude of reasons. Differentiating these settings and purposes might prove interesting.

The series of position statements could be broken down into many 
further research projects. Any research effort which would seek to reduce the ambiguity in the use of the term "diagnosis" could aid in reducing miscommunication and possibly foster closer cooperation between two caring professions. Other areas that could be focused on in future research are the individual perceptions of otolaryngologists of the need to "supervise" speech pathologists; the physician's view of the success of a speech pathologist's interventions; and the physician's view of the use of behavioral procedures such as voice intervention as an alternative to medical procedures such as surgery. 


\section{Bibliography}

ALBERTI, P.W. (1980). Panel discussion: the auditory training of the otolaryngologist. Transcripts of the Ninth Symposium: Care of the Professional Voice.

ARNOLD, G.E. (1958). Special features and new viewpoints of phoniatric practice in New York. Foila Phoniatrica, 10, 96-111.

ARONSON, A.E. (1980). Clinical Voice Disorders. New York: Brian C. Decker.

BLOCH, C.S., GOULD, W.J. \& HIRANO, M. (1981). Effect of voice therapy on contact granuloma of the vocal folds. Annals of Otolaryngology, 90, 48-52.

BLOCH, P. (1959). Goals and limits of vocal analysis. Logos, 2(2), $111-118$.

BOONE, D.R. (1977). The voice and voice therapy. Englewood Cliffs: Prentice-Hali, Inc.

BRODNITZ, F.S. (1966). Goals, results and limitations of vocal rehabilitation. Archives of Otolaryngology, 77, 148-156.

COOPER, M. \& NAHUM, A.M. (1967). Vocal rehabilitation for contact ulcers of the larnyx. Archives of 0tolaryngology, 85, 41-46.

COOPER, M. (1971). Modern techniques of vocal rehabilitation for functional and organic dysphonia. In Travis, L.E. (Ed) Handbook of speech pathology and audiology. New York: Appleton-Century Crofts.

COOPER, M. (1973). Modern techniques of vocal rehabilitation. Springfield: Charles C. Thomas, Publishers.

DEWEESE, D.D. \& LILLYWHITE, H. (1960). Speech disorders. In Deweese, D.D. \& Saunders, W.H. (Ed.) Textbook of otolaryngology. St. Louis: C.V. Mosby Co.

DICKSON, F. (1974). Communication disorders: Remedial principles and practices. Gienview: Scott Foresman \& Co.

Directory of Medical Specialists: Twenty-First Edition (1983-84). Chicago: Carquis who's who Inc.

EDWARDS, A.L. (1957). Techniques of attitude scale construction. New York: Appleton Century-Crofts, Inc. 
ENGLE, R.L. \& DAVIS, B.J. (1963). Medical diagnosis: present, past, and future. Archives of Internal Medicine, 112, 512-529.

FRITZELL, E. (1980). Training programs in phoniatrics. Folia Phoniatrica, 32, 88-102.

GREENE, M.C.L. (1980). The voice and its disorders. Philadelphia: J.B. Lippincott Co.

LILLYWHITE, H. (1961). Toward a philosophy of professional behavior. ASHA, 2, 39-42.

MCFARLANE, S.C., FUJIKI, M. \& BRINTON, B. (1984) Coping with communication handicaps. San Diego: College Hill Press, Inc.

MILLER, S.Q. \& MADISON, C.L. (1984). Public school voice clinics, part I: a working model. Language, Speech, and Hearing Services in the Schools, $15,51-57$.

MILLISEN, R. (1971). Methods of evaluation and diagnosis of speech disorders. In Travis, L.E. (Ed.) Handbook of speech pathology and audiology. New York: Appleton-Century Crofts.

MINIFIE, F.D. (1983a). ASHA responds to President of American Council of Otol arymgology-Head and Neck Surgery. ASHA, 25(5), 23.

MINIFIE, F.D. (1983b, October 13). Address to the Joint Meeting of the Oregon Speech-Language-Hearing Association and the Washington Speech-Language-Hearing Association.

MINIFIE, F.D. (1983c). President's page. ASHA, 25(11), 15.

MOORE, G.P. (1981). A sketch of the partnership between speech pathologists and larngologists. Transcripts of the Tenth Symposium: Care of the Professional Voice.

NATIONAL INSTITUTE OF NEUROLOGICAL COMMUNICATION DISORDERS AND STROKE (1977). Otorhinolaryngology: Manpower Resources and Needs.

Monograph \#18.

OLDRING, D. (1984). Interview in American Speech-Language-Hearing Association Journal, 26(4), 21-24.

O'NEILL, J.J. \& MCGEE, J.A. (1962). Management of benign 1 aryngeal tumors in children. Annals of Otorhinol aryngology, 71, 480-488.

PERKINS, W.H. (1977). Speech pathology: An applied behavioral science. Saint Louis: C.V. Mosby, Co

SEGRE, R. (1971). The current world status of logopedics and phoniatrics. Folia Phoniatrica, 23, 155-197. 
WILBUR, L.A. (1982). ASHA responds to American Council of Otol aryngology statement. ASHA, 24(8), 509.

WILLIAMSON, A.B. (1946). Symposium on adequacy of training of voice specialists. Quarterly Journal of Speech, 32(2), 145-160. 
APPENDIX A

COVER LETTER TO ALL RESPONDENTS 


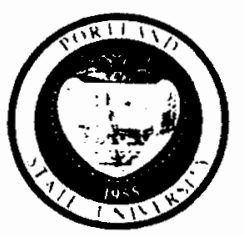

July 1, 1985

Dear physician,

The field of Speech Pathology is changing rapidly. We are entering new areas and expanding our expertise in others. Voice disorders, which you treat as a medical specialist, is one of the areas where we find ourselves becoming important entities in the re-education process.

The question of the role of the Speech Pathologist is controversial at this point as evidenced by a recent position statement by the American Academy of Otolaryngologists and by subsequent replies to this statement by the American Speech/Language/Hearing Association. This questionnaire is designed to anonymously assess how individual otolaryngologists view the Speech Pathologist's role in working with voice disordered patients specifically.

I believe your views are crucial. When we understand your views, we can appropriately focus our efforts to increase communication between the allied fields.

Please sign and date the consent form, fill out the questionnaire, and return both in the enclosed envelope. Your response will be number coded to ensure anonymity.

Please contact me if you have any questions and thank you so very much for your prompt return of this questionnaire.

Gudith P.B. Cross

Graduate Student

Robert L. Casteel, Ph.D , ASHA Fellow Thesis Advisor 
APPENDIX B

INFORMED CONSENT FORM 


\section{INFORMED CONSENT FORM}

I, hereby agree to serve as a subject in the research project of Judith P.B. Cross on the attitudes of otolaryngologists towards Speech Pathologists working with voice disordered clients, conducted under the supervision of the Portland State University Speech and Hearing Sciences Program.

I understand that the study involves answering a series of questions and that possible risks to me associated with this study are inconvenience and a demand on my time (approximately 15 minutes).

It has been explained to me that the purpose of the study is to identify needs to improve relations between otolaryngologists and Speech Pathologists.

I have been assured that my response form has been number coded to ensure anonymity. The researcher, Judith P.B. Cross, has offered to answer any questions I may have about the study.

I have read and understand the foregoing information.

Date Signature

If you experience problems that are the result of your participation in this study, please contact Victor G. Dahl, Office of Graduate Studies and Research 105 Neuberger Hall, Portland State University, 229-3423. 
APPENDIX C

QUESTIONNAIRE 
Please answer the following questions based on your own understanding/knowledge.

How much education must a speech pathologist have?
Two Year Degree Master's
Bachelor's
Doctoral

What is required for a speech pathologist to be certified by the American Speech-Language-Hearing Association (check as many as you believe apply)?

National Examination

Master's Degree
300 Hours Direct Contact

Fellowship Year

What voice disorders are speech pathologists most helpful with (check as many as you believe apply)?

Development of voice after laryngectomy:

Rehabilitation of voice after surgical management of tumors such as papilloma, polyps, cysts:

Rehabilitation for laryngeal trauma:

Vocal restoration for unilateral vocal fold paralys is with teflon implant:

Vocal disorders with no apparent pathology:

Management of vocal nodules before and as an alternative to surgery:

Management of contact ulcers before and as an alternative to surgery:

What textbook has most influenced your knowledge about speech pathologists' work with voice disorders?

Please circle a number from 1 to 7 for each statement: $\begin{aligned} & \text { Agree } \\ & 1\end{aligned} \underline{2} \underline{4} \underline{4} \underline{6} \underline{7}$

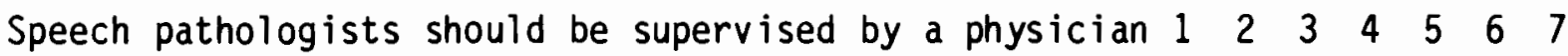
for diagnosis of voice problems.

Speech pathologists should be supervised for voice $\quad \begin{array}{lllllll}1 & 2 & 3 & 4 & 5 & 6 & 7\end{array}$ management by a physician .

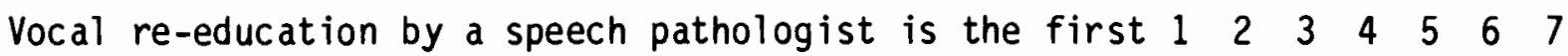
treatment of choice in the management of vocal nodules.

The diagnosis of voice problems is in the domain of $\begin{array}{lllllll}1 & 2 & 3 & 4 & 5 & 6 & 7\end{array}$ the otolaryngologist solely.

When a speech pathologist consults with a physician but

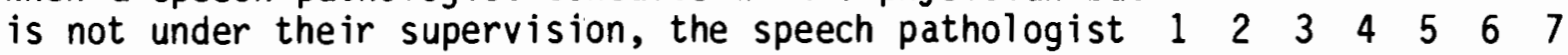
is not operating in the best interests of the patient.

The use of a speech pathologist in voice problems is $\begin{array}{lllllll}1 & 2 & 3 & 4 & 5 & 6 & 7\end{array}$ unnecessary unless problems with phonation occur after surgery. 
Speech pathologists offer an effective alternative to $\begin{array}{lllllll}1 & 2 & 3 & 4 & 5 & 6 & 7\end{array}$ some surgeries of the vocal mechanism.

Speech pathologists I come in contact with generally $\begin{array}{llllllll}1 & 2 & 3 & 4 & 5 & 6 & 7\end{array}$ teach the voice disordered patient more appropriate

techniques of phonation.

Approximate number of patients seen per month (check one):

Less than $100 \_100-150 \_150-200 \_$Over 200

Approximate number of voice disordered patients seen per year (check one):

Less than 5 _ $5-20 \_21-100 \_$Over 100

County and State where you practice:

Approximate population of area you practice in (check one):

Less than $25,000+25-50,000 \_50-100,000$

$100-250,000 \_250-1,000,000 \_$Over $1,000,000$

EDUCATION

\begin{tabular}{|c|c|}
\hline Location & $\begin{array}{c}\text { Approx. } \\
\text { Date }\end{array}$ \\
\hline
\end{tabular}

Medical Degree

Otol aryngology Residency

Surgery

Research Training

Other Significant Training (please list):

\begin{tabular}{ll}
$\begin{array}{c}\text { Approx. } \\
\text { Date }\end{array}$ & $\begin{array}{l}\text { Any Speech Path- } \\
\text { ology Exposure? }\end{array}$ \\
\hline
\end{tabular}

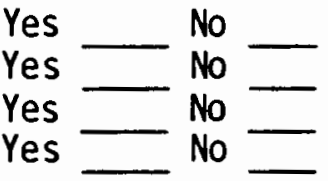

Yes
Yes
Yes

Have you ever received any education in speech pathology (such as CME courses)?

Yes _ No N_ If yes, where? When

Is speech pathology education available in your community? Yes No Have you ever made a referral to a speech pathologist for a voice disorder?

Yes No If yes, how many in a year (approximate)?

For what disorders? 
Have you ever received referrals from a speech pathologist for a voice disorder?

Yes No If yes, how many in a year (approximate)?

For what disorders?

How much direct contact do you have with speech pathologists (including calls)?

More than once per month

Once per month

Once every few months Less than once per year 
APPENDIX D

COVER LETTER TO NEVADA RESPONDENTS 
Departinent of Speech Pathology and Audiology

Mackey Soence Builuing

Foom: $: 08$

Rero, Nevida $875,5, n$

(70), $794-48 \mathrm{~d} 7$

July 1,1985

Dear physician,

I would be grateful if you could take a few moments to complete the enclosed form and mail it in the enclosed envelope. A friend of mine is conducting a survey in three states and has asked that we in Nevada participate.

Thank you for your assitance.

Sincerely,

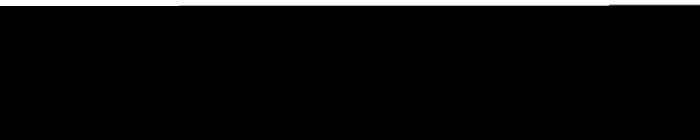

Stepinen C. Mrarartane, Pn.D.

Professor and Chairman

Speech Pathology and Audiology

Encs.

SCM: jfm 
APPENDIX E

FOLLOW-UP POSTCARD 
Dear Physician:

Approximately two meeks ago you received a questionnaire in the mail concerning your attitudes toward speech pathologists working with voice disordered patients.

The results of this research are only significant if many physicians respond. Please, let your views be represented. They are extremely important.

If you have misplaced your questionnaire, please write or leave a phone message for me at the following location:

Judith P.B. Cross

\% Portl and State University Speech \& Hearing Sciences

P.0. Box 751

Portl and, Oregon 97207

(503) 229-3533 